\title{
ADAPTIVE FULL-SPECTRUM SOLAR ENERGY SYSTEMS \\ Cross-Cutting R\&D on adaptive full-spectrum solar energy systems for more efficient and affordable use of solar energy in buildings and hybrid photobioreactors
}

Semi-Annual Technical Progress Report

August 31, 2002 - April 30, 2003

Byard D. Wood, Project Director

Mechanical Engineering Department

Mail Stop 312

University of Nevada, Reno

Reno, NV 89557
Jeff D. Muhs, Principal Investigator

Oak Ridge National Laboratory

2360 Cherahala Blvd.

Bldg. NTRC, MS 6472

Knoxville, TN 37932

\section{PREPARED FOR}

\section{NATIONAL ENERGY TECHNOLOGY LABORATORY \\ THE UNITED STATES DEPARTMENT OF ENERGY}

DOE Award Number DE-FC26-01NT41164

Energy Crosscutting Science Initiative

Office of Energy Efficiency and Renewable Energy 


\begin{abstract}
ABTRACT
This RD\&D project is a three year team effort to develop a hybrid solar lighting (HSL) system that transports day light from a paraboloidal dish concentrator to a luminaire via a large core polymer fiber optic. The luminaire can be a device to distribute sunlight into a space for the production of algae or it can be a device that is a combination of day lighting and florescent lighting for office lighting. In this project, the sunlight is collected using a one-meter paraboloidal concentrator dish with two-axis tracking. The secondary mirror consists of eight planarsegmented mirrors that direct the visible part of the spectrum to eight fibers (receiver) and subsequently to eight luminaires. This results in about 8,200 lumens incident at each fiber tip. Each fiber can illuminate about $16.7 \mathrm{~m}^{2}\left(180 \mathrm{ft}^{2}\right)$ of office space. The IR spectrum is directed to a thermophotovoltaic array to produce electricity. This report emphasizes the design of the thermophotovoltaic receiver and the whole system simulation model.
\end{abstract}

\title{
DISCLAIMER
}

This report was prepared as an account of work sponsored by an agency of the United States Government. Neither the United States Government nor any agency thereof, nor any of their employees, makes any warranty, express or implied, or assumes any legal liability or responsibility for the accuracy, completeness, or usefulness of any information, apparatus, product or process disclosed, or represents that its use would not infringe privately owned rights. Reference herein to any specific commercial product, process, or service by trade name, trademark, manufacturer, or otherwise does not necessarily constitute or imply its endorsement, recommendation, or favoring by the United States Government or any agency thereof. The views and opinions of authors expressed herein do not necessarily state or reflect those of the United States Government or any agency thereof.

\section{PREFACE}

This report is a joint effort between Oak Ridge National Laboratory and the University of Nevada, Reno, as such it satisfies the reporting requirements for the University and ORNL as the $\mathrm{M} \& \mathrm{O}$ for this project. The original award had budget period 2 beginning August 2, 2002. However, due to some complications and an extensive project review process, budget period 2 was not authorized until May $1^{\text {st }}, 2003$. Consequently, the amount of progress during this reporting period was rather limited since most of the funds for budget period 1 had already been expended prior to this reporting period. Nonetheless, the work continued at The University of Nevada, Reno and The University of Wisconsin. The technical progress reported herein will emphasize the work at these two institutions. 


\section{TABLE OF CONTENTS}

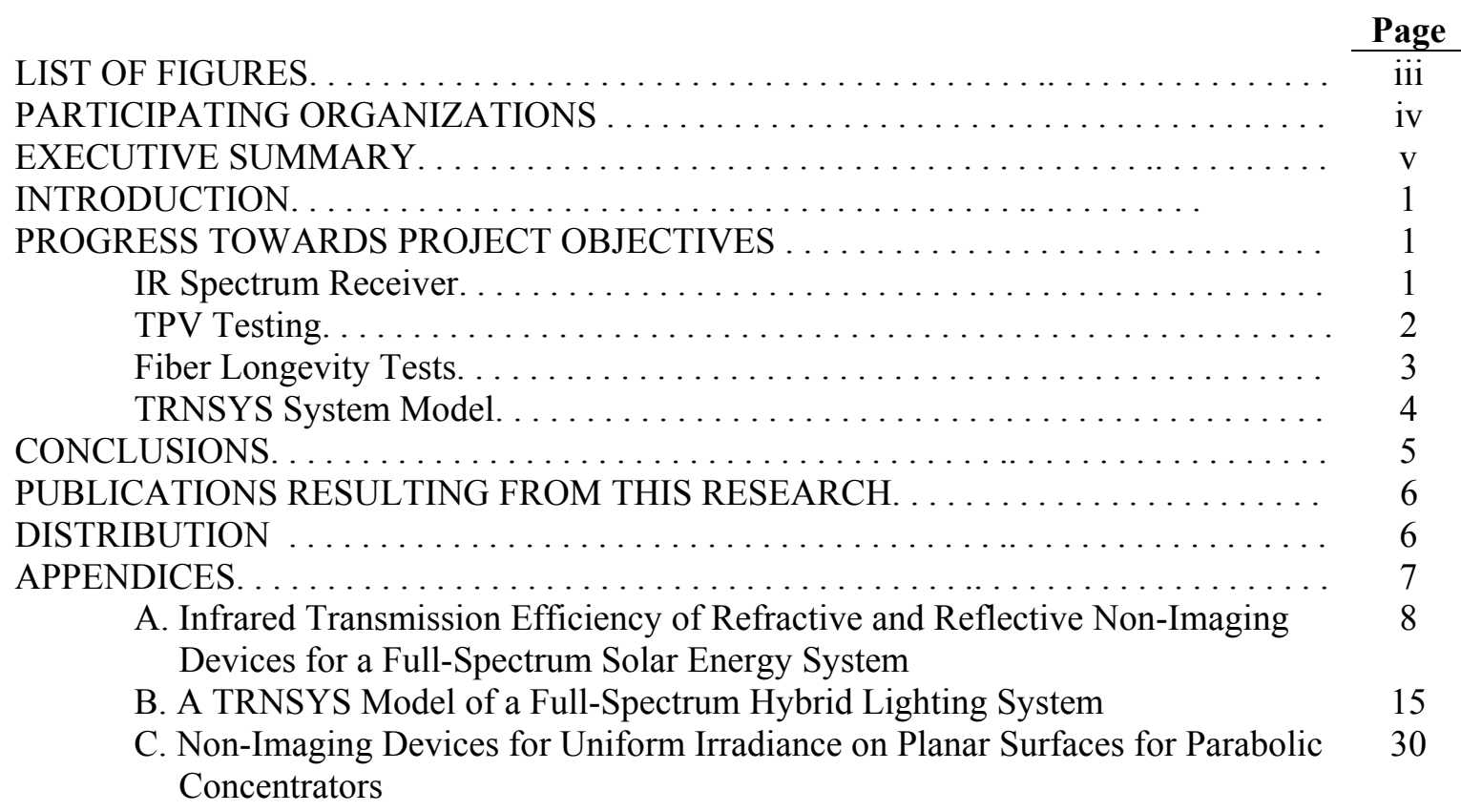

\section{LIST OF FIGURES}

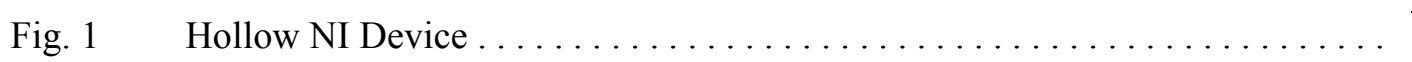

Fig. 2 NI Device Test System. . . . . . . . . . . . . . . . . .

\begin{tabular}{c} 
Page \\
\hline 3 \\
3
\end{tabular}




\section{PARTICIPATING ORGANIZATIONS}

\begin{tabular}{|l|c|l|}
\hline Organization & Abbreviation & Principal Investigator \\
\hline University of Nevada, Reno & UNR & Byard Wood \\
Mechanical Engineering-312 & & \\
Reno, NV 89577 & & \\
\hline Oak Ridge National Lab & ORNL & Jeff Muhs \\
P.O. Box 2009, MS-8058 & & \\
Oak Ridge, TN 32831 & & \\
\hline Honeywell Technology & Honeywell & Robert Schnell \\
Center & & \\
3660 Technology Drive & & \\
Minneapolis, MN 55418 & & \\
\hline JX Crystals, Inc. & JXC & Lewis Fraas \\
1105 12th Avenue NW & & \\
Suite A2 & & \\
Issaquah, WA 98027 & & \\
\hline Ohio University & OU & David Bayless \\
Dept. of Mechanical & & \\
Engineering & & \\
248 Stocker Center & & \\
Athens, OH 45701-2979 & & \\
\hline Rensselaer Polytechnic & RPI & Nadarajah Narendran \\
Institute & & \\
Lighting Research Center & & \\
21 Union Street & & \\
Troy, NY 12180-3352 & & \\
\hline Science Application & & \\
International Corporation & SAIC & Robin Taylor \\
9455 Towne Centre Drive & & \\
San Diego, California 92121 & & \\
\hline 3M Company & & \\
3M Corporate Process & & \\
Technology Center & & \\
St. Paul, MN 55144-1000 & & \\
\hline TVA Public Power Institute & & \\
1101 Market Street, MR 2T & & \\
Chattanooga, TN 37402-2801 & & \\
\hline University of Arizona & & \\
Department of Agricultural \\
and Biosystems Engineering \\
507 Shantz Building & & \\
Tucson, AZ 85721 & & \\
\hline University of Wisconsin & & \\
Solar Energy Lab & & \\
Madison, WI 53706 & & \\
\hline
\end{tabular}

The contributions of each of these individuals in the preparation of this report are gratefully acknowledged. 


\section{EXECUTIVE SUMMARY}

This RD\&D project is a three year team effort to develop a hybrid solar lighting (HSL) system that transports day light from a paraboloidal dish concentrator to a luminaire via a large core polymer fiber optic. The luminaire can be a device to distribute sunlight into a space for the production of algae or it can be a device that is a combination of day lighting and florescent lighting for office lighting. In this project, the sunlight is collected using a one-meter paraboloidal concentrator dish with two-axis tracking. The secondary mirror consists of eight planarsegmented mirrors that direct the visible part of the spectrum to eight fibers (receiver) and subsequently to eight luminaires. This results in about 8,200 lumens incident at each fiber tip. The IR spectrum is directed to a thermophotovoltaic array to produce electricity. This report describes the technical progress from August 31, 2002 through April 30, 2003.

The goals of this project are to:

1. Determine technical feasibility of using full-spectrum solar energy systems to enhance the overall sunlight utilization in buildings and biomass production rates of photobioreactors. This will be accomplished by developing a benchmark prototype system.

2. Determine the commercial viability of using full-spectrum solar energy systems to enhance the overall sunlight utilization in buildings and biomass production rates of photobioreactors. This will be accomplished by determining those characteristics that characterize performance, efficiency, reliability, durability and ultimately minimum cost potential.

3. Demonstrate the HSL technology in a building application and a photobioreactor application. The emphasis in developing the demonstration systems will be to meet performance objectives at minimum cost.

During the reporting period, the project team made progress towards the completion of the TRNSYS Full-Spectrum Solar Energy System model, the IR receiver design, and the fiber durability test devices. Accomplishments for this period are:

1. Finalization of the IR receiver design and development of the test system. Mr. Dan Dye's Masters Thesis, available on the project website (www.energy.unr.edu/lighting), details the design of the IR receiver. Work was begun on the test system for the TPV array using a primary mirror similar to the Benchmark mirror used at ORNL.

2. TRNSYS simulations were performed to determine effectiveness of the hybrid lighting technology across the United States. Hybrid lighting systems located in Tucson, AZ and Honolulu, HI performed best with break-even capital costs of $\$ 2,050$ /module for a 5 year analysis period and $\$ 2,800$ /module based on a 10 year analysis period.

3. Test devices have been built that will test the long-term performance of the $3 \mathrm{M}$ optical fibers as well as other fibers. These devices will test the material failure associated with bending fatigue and the optical degradation associated with long-term exposure to high luminous flux. These tests will start with the $3 \mathrm{M}$ fibers, but will be setup so that other fibers and fiber bundles may be tested for screening purposes as well. 


\section{INTRODUCTION}

This project is part of the FY 2000 Energy Efficiency Science Initiative that emphasized Cross-Cutting R\&D in Solicitation No.: DE-PS36-00GO10500. It is a three year research project that addresses key scientific hurdles associated with adaptive, full-spectrum solar energy systems and associated applications in commercial buildings and new solar photobioreactors.

The scope of work has been divided into three phases that roughly coincide with each budget period, viz.:

\section{Phase I. Assess Technical Feasibility}

Determine technical feasibility of using full-spectrum solar energy systems to enhance the overall sunlight utilization in buildings and biomass production rates of photobioreactors. This will be accomplished by developing a benchmark prototype system that can evaluate this unique solar lighting technology.

\section{Phase II. Assess Commercial Viability}

Determine the commercial viability of using full-spectrum solar energy systems to enhance the overall sunlight utilization in buildings and biomass production rates of photobioreactors. This will be accomplished by determining those characteristics that characterize performance efficiency, reliability, durability and ultimately minimum cost potential.

\section{Phase III. Assess System Affordability}

Demonstrate the HSL technology in a building application and a photobioreactor application. The emphasis in developing the demonstration systems will be to meet performance objectives at minimum cost.

\section{PROGRESS TOWARDS PROJECT OBJECTIVES}

The emphasis during this reporting period has been on completing the design of the IR receiver, completing the TRNSYS system model, and developing the fiber durability test systems. A brief summary of each investigation is given below and the details are provided in technical papers that have been drafted and included in the Appendices to describe the progress towards establishing technical feasibility.

IR Spectrum Receiver: In BP1, a study was performed that determined the optimal cross-sectional shape of the non-imaging (NI) device for the IR TPV array is a rectangular shaped tube. This tube will give the best balance of flux uniformity and transmission efficiency ${ }^{1}$.

A second study was performed that examined the transmission differences between hollow reflective tubes and total internal reflecting (TIR) tubes $^{2}$ [Appendix A]. The results from that study showed that a hollow internal reflecting tube provides the best performance/cost ratio for the transmission of the IR irradiance and is substantially shorter in length than the TIR tube. Using ray trace software (TracePro), the performance of the IR portion of the collector/receiver is as follows:

1 Dye, D., Wood, B.D., Fraas, L., and Muhs, J., "Optical Design of an Infrared Non-Imaging Device for a FullSpectrum Solar Energy System," Proceedings of the ASME International Solar Energy Society Conference, Hawaii, 2003

2 D. Dye, B. Wood, "Infrared Transmission Efficiency of Refractive and Reflective Non-Imaging Devices for a Full-Spectrum Solar Energy System”, Non-Imaging Optics: Maximum Efficiency Light Transfer VII, SPIE, 2003 
- $61 \%$ transmission through the secondary mirror from 0.7-1.8 micron

- $86 \%$ efficient through non-imaging device

- $212 \mathrm{~W}$ incident on TPV array, $205 \mathrm{~W}$ usable

- $\quad$ Total TPV output $=37 \mathrm{~W}(205 \mathrm{~W}$ x $18 \%$ efficiency $)$

- Changing to a square 96 cell array would increase output to $44 \mathrm{~W}$.

- 96 cell array has a $19 \%$ increase in power production and a $2 \%$ increase in overall system efficiency

There is obviously room for improvement in the transmission of the secondary mirror. A sharper reflection/transmission cutoff point in the transition from visible light to IR would increase the IR transmission and thus usable irradiance on the TPV array.

The abstract from the study published on the refractive and reflective tubes, published in the 2003 SPIE conference, is given below and the full-text version of this paper can be found in Appendix A and on the website: www.energy.unr.edu/lighting

A solar collector/receiver for a full-spectrum solar energy system is being designed by a research team lead by Oak Ridge National Laboratory and the University of Nevada, Reno ${ }^{1,2}$. This solar energy system is unique in that it utilizes the majority of the solar spectrum. The collector/receiver is a modified Cassegrain system that uses a large parabolic mirror and a secondary mirror comprised of multiple planar segments. The secondary mirror segments are coated with a spectrally selective cold mirror coating that lets the infrared (IR) energy pass through while reflecting the visible light.

The focus of this paper is on determining whether a refractive or a reflective non-imaging (NI) tube will produce the most uniform irradiance of the IR energy on the thermophotovoltaic (TPV) array. It has been shown that a rectangular NI tube will work well for the prototype system ${ }^{3}$. The results herein show that a reflective NI tube will perform best for this system, with a short length, minimum/maximum flux ratio of 0.94 and power output of $37 \mathrm{~W}$. It is also shown that a square shaped TPV array can increase the optical efficiency by $9 \%$ and the overall system efficiency by $2 \%$.

TPV Testing: Currently, a collector and NI device are being built to test the performance of the JX Crystals TPV array. The collector is a spun aluminum parabolic mirror with ReflecTech coating, the cold mirror is a Navitar Coating cold mirror, and the NI device has Navitar Coatings enhanced aluminum mirror surface, with an average reflectivity of $96 \%$. A cooling circuit is being built so the temperature of the TPV array can be controlled during testing. Forced cooling of the array is most likely necessary since the solder melts at $130^{\circ} \mathrm{C}$. Figure 1 shows a picture of the NI tube, and Figure 2 shows a picture of the primary mirror, tracking system, NI tube, and chilled water supply lines. 


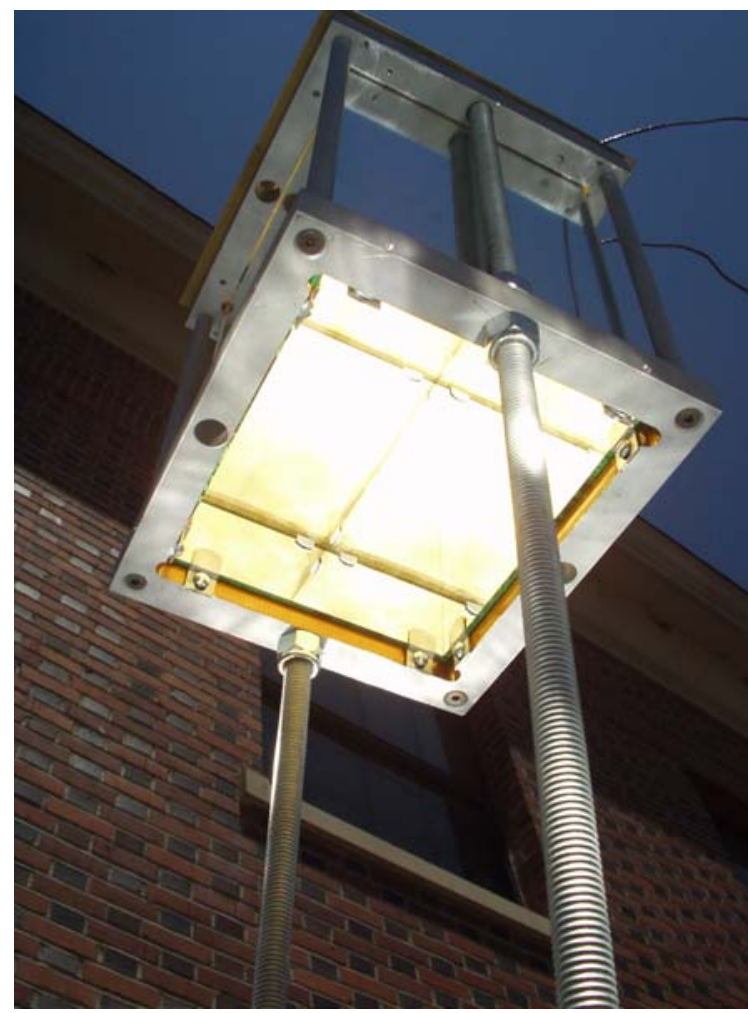

Figure 1: Hollow NI Device

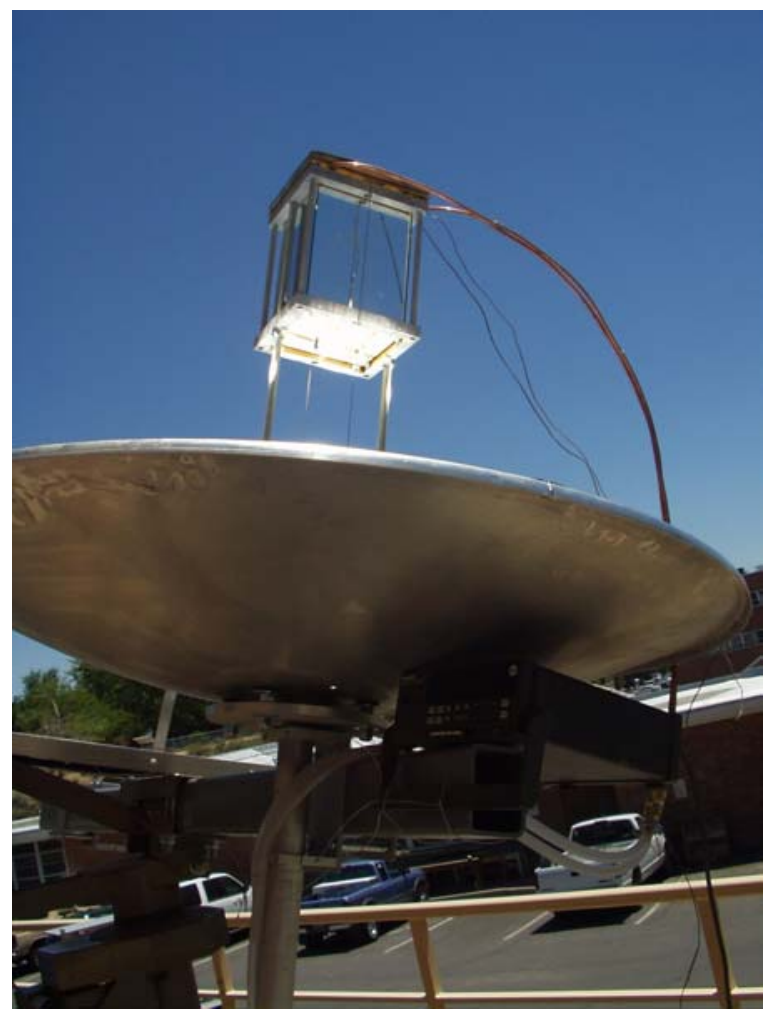

Figure 2: NI Device Test System

Fiber Longevity Tests: Two systems are under development and implementation at UNR that will test the longevity of the fiber optics. These test systems are designed to test the ability of the fibers to withstand high light flux for extended periods of time and endure the repetitive bending motion and climatic exposure that the fibers will see on a rooftop tracking system.

The first system, called the bending test, holds a fiber fixed at one end and bends the other end $180^{\circ}$ in a plane to simulate the motion of daily tracking. The durability of the fibers has been tested in two different cold conditions. The apparatus shown in Figures 3 and 4 bends the fibers over a 9" radius surface in two directions. The length of time required to complete one bending cycle is variable, and has been set to 1 revolution per minute for these tests. The preliminary data are shown, but more tests are required in order to increase the number of samples to a reasonable number.

$$
\begin{aligned}
& +5 \text { degrees } C: \text { average lifespan }=11,353 \text { cycles @ } 1 \mathrm{rpm} \\
& 0 \text { degrees C: average lifespan }=14,335 \text { cycles @ 1rpm }
\end{aligned}
$$

The second system, called the High Flux test system, will concentrate visible sunlight to the levels seen in the benchmark system and expose fibers to this flux for extended periods. The transmission properties of the fiber will be characterized before the tests, and periodically during the tests, to monitor absorption bands that may develop as the fiber ages.

Both of these test systems are easily modifiable to accomodate different diameters of fibers, so that other brands may be tested. The systems can also be used to test fiber bundles, which may be used in the Alpha collector/receiver system. 
TRNSYS System Model: During the latter half of BP1 work continued on the TRNSYS Hybrid Lighting Model. The work has resulted in a software tool that can simulate the monetary and energy benefits associated with hybrid lighting technology. All of the physical parameters of a hybrid lighting system are included as variables within the software. The software allows the hybrid lighting team to make design decisions based upon computer predictions of the hybrid lighting system performance.

The hybrid lighting system is modeled using the transient system simulation program TRNSYS. The TRNSYS model is implemented using interconnected components, which include a weather generator, radiation processors, a hybrid lighting model, a building model, building schedules, utility rate schedules, and output components. The results from the simulation include the annual energy and monetary savings gained from the hybrid lighting system. An economic model has been incorporated into the hybrid lighting model to calculate the break-even capital cost of a hybrid lighting system based on the annual savings.

A narrow-band and wide-band hybrid lighting model has been developed. The wide-band model uses direct normal solar radiation from either a TMY2 data file or the TRNSYS weather generator. The incoming direct normal radiation is weighted by the average spectral properties of the hybrid lighting components which include concentrator reflectance, secondary element transmittance and reflectance, thermophotovoltaic quantum efficiency, light fiber attenuation, and luminaire efficiency. The wide-band model is simpler to implement than the narrow-band model and was developed first.

The narrow-band model uses TMY2 data or the TRNSYS weather generator to obtain the magnitude of the direct normal radiation, but the direct normal spectral distribution is predicted based on the atmospheric transmission model SMARTS. The narrow-band model predicts the direct normal spectral radiation at five nanometer bandwidths. Next it reads the available spectral component data, applies the component data to the solar spectral distribution, and calculates the amount of light and electricity that is generated by the system. The outputs from both models include the light produced by the hybrid lighting system as well as electricity generated by the TPV. The narrow-band model takes only slightly more time to run than does the wide-band model. It is recommended that the narrow-band model be used to assess system performance.

Within TRNSYS, the light output from the hybrid lighting system model is sent to the building model. The building is modeled using the TRNSYS type 56 multi-zone building model. Type 56 is a FORTRAN subroutine which is designed to provide detailed thermal models of buildings. The model consists of two windowless $2500 \mathrm{~m} 2$ zones. One zone uses efficient fluorescent lighting and the other zone uses hybrid lighting with dimmable fluorescent auxiliary lighting. Identical schedules in the two zones simulate the heating, cooling, and ventilation of a typical mixed-use environment. Gains in the model account for the people, computers, and lights in the building. Cooling in the building is supplied using a chiller with a constant COP of 3 and heating loads are met using an $80 \%$ efficient natural gas furnace. Using local utility rate schedules, energy costs can be calculated for the two zones of the building model with the difference representing the energy savings due to the hybrid lighting system.

The hybrid lighting economics model calculates the break-even capital cost of a hybrid lighting system based on the system energy savings. The break-even capital cost is defined as the initial cost of the hybrid lighting system that will provide a life cycle savings (LCS) of zero over the economic lifetime. At this point in the design stage, realistic component prices are not available for determining economic parameters such as years to payback, LCS, or return on investment. Instead the break-even capital cost was calculated to be used as a price target where the energy savings predicted by the TRNSYS model will economically compensate for the system cost. 
Simulations were performed to determine effectiveness of the hybrid lighting technology across the United States. Hybrid lighting systems located in Tucson, AZ and Honolulu, HI performed best with break-even capital costs of $\$ 2,050 /$ module for a 5 year analysis period and $\$ 2,800 /$ module based on a 10 year analysis period. Using longer economic analysis periods results in higher break-even capital costs of $\$ 3,554$ and $\$ 2,587$ for a 20 year period and $\$ 3,902$ and $\$ 2,856$ for a 30 year period, respectively.

The abstract from the ISES 2003 paper: "A TRNSYS Model of a Full Spectrum Hybrid Lighting System", is shown below and the full-text version of this paper can be found in Appendix B and on the website: www.energy.unr.edu/lighting

Hybrid lighting is a new approach to lighting that integrates light from natural and electric sources. A two-axis tracking concentrator collects beam radiation which is reflected onto a mirror that divides the solar radiation into infrared and visible spectra. The visible light is distributed through optical and combined with fluorescent lighting in specially designed luminaires. The infrared portion of the spectrum is used to generate electricity using a thermal photovoltaic array. A simulation of a hybrid lighting system has been created using the TRNSYS transient simulation program. The simulation incorporates the spectral properties of the hybrid lighting components as well as the spectral distribution of the incoming solar radiation that is based upon output from the SMARTS atmospheric transmittance model. An office building model is coupled with the hybrid lighting simulation to predict the annual energy impact upon lighting, heating, and cooling loads. Simulations were performed in six locations within the United States. Hybrid lighting systems performed best in Honolulu, HI and Tucson, AZ justifying system capital costs of \$2,800 and \$2,050 per module, respectively, based on a 10 year payback period.

\section{CONCLUSIONS}

During the reporting period, the team members still working on the project made progress in a few different areas that will assist in the development of the hybrid solar lighting system. The R\&D in this period has been directed towards the finalization of the IR receiver, fiber durability tests, and the TRNSYS system models. These advancements are outlined below:

1. Finalization of the IR receiver design and development of the test system. Dan Dye's Masters Thesis, available on the project website (www.energy.unr.edu/lighting), details the design of the IR receiver. The final design consists of a hollow rectangular shaped tube with an enhanced aluminum coating ( $96 \%$ average reflectivity) front surface. This non-imaging tube will produce a flux variation of $\pm 3 \%$ with a high energy transfer through the tube. Work was begun on the test system for the TPV array using a primary mirror similar to the Benchmark mirror used at ORNL and the hollow non-imaging tube.

2. TRNSYS simulations were performed to determine effectiveness of the hybrid lighting technology across the United States. Hybrid lighting systems located in Tucson, AZ and Honolulu, HI performed best with break-even capital costs of $\$ 2,050 /$ module for a 5 year analysis period and $\$ 2,800 /$ module based on a 10 year analysis period.

3. Test devices have been built that will test the long-term performance of the $3 \mathrm{M}$ optical fibers as well as other fibers. These devices will test the material failure associated with bending fatigue and the optical degradation associated with long-term exposure to high luminous flux. These tests will start with the $3 \mathrm{M}$ fibers, but will be setup so that other fibers and fiber bundles may be tested for screening purposes as well. Preliminary results show that the fibers can handle on average 11,353 cycles at $+5^{\circ} \mathrm{C}$ and 14,335 cycles at $0^{\circ} \mathrm{C}$. These tests are ongoing, so as the number of samples increases so will the accuracy and credibility of the tests. 


\section{PUBLICATIONS RESULTING FROM THIS RESEARCH}

During this reporting period, three conference papers were published, viz.:

Infrared Transmission Efficiency of Refractive and Reflective Non-Imaging Devices for a FullSpectrum Solar Energy System SPIE International Symposium - Optical Science and Technology, SPIE's 48th Annual Meeting, San Diego, CA, August 3-8, 2003 [Appendix A]

A TRNSYS Model of a Full-Spectrum Hybrid Lighting System ISES SOLAR WORLD CONGRESS 2003, Göteborg, Sweden, June 14-19, 2003 [Appendix B]

Non-Imaging Devices for Uniform Irradiance on Planar Surfaces for Parabolic Concentrators, ASES 2003 Annual Conference, Austin, TX, June 16-25, 2003 [Appendix C]

\section{DISTRIBUTION}

$>$ NETL AAD Document Control

$>$ Frank "Tex" Wilkins, DOE

$>$ Lew Pratsch, DOE

$>$ Glenn Strahs, DOE

$>$ Joel S. Chaddock, NETL

$>$ Bonnie Dowdell, NETL

$>$ David J. Bayless, Ohio University

$>$ William Beckman, University of Wisconsin

$>$ Clinton Berry, TN Dept. of Economic \& Community Dev. Energy Division

$>$ Joel L. Cuello, University of Arizona
Roger Davenport, Science Applications International Corporation

$>$ David R. Dinse, TVA Public Power Institute

$>$ Lewis Fraas, JX Crystals Inc

$>$ Jason B. Keyes, JX Crystals Inc.

$>$ Sandy Klein, University of Wisconsin

$>$ Dave McNeil, Nevada Energy Office

$>$ Jeff Muhs, Oak Ridge National Laboratory

$>$ Nadarajah Narendran, Rensselaer Polytechnic Institute

$>$ Ramesh Raghavan, Rensselaer Polytechnic Institute

$>$ Jennifer Sahlin, 3M

$>$ Robert Schnell, Honeywell Laboratories

$>$ Robin W. Taylor, Science Applications International Corporation

This report is posted on web site www.energy.unr.edu/lighting

\section{APPENDICES}

Each appendix is a self contained report that contributes to the determination of the technical feasibility of Adaptive Full Spectrum Solar Energy Systems.

\section{APPENDIX A}

Infrared Transmission Efficiency of Refractive and Reflective Non-Imaging Devices for a Full-Spectrum Solar Energy System, D. Dye and B. Wood, University of Nevada, Reno, SPIE International Symposium - Optical Science and Technology, SPIE's 48th Annual Meeting, San Diego, CA, August 3-8, 2003 Proceedings of SPIE, [Nonimaging Optics: Maximum Efficiency Light Transfer VII, 2003] 


\section{APPENDIX B}

A TRNSYS Model of a Full-Spectrum Hybrid Lighting System, G.O. Schlegel, S.A. Klein, and W.A. Beckman, University of Wisconsin, Proceedings of the International Solar Energy Society SOLAR WORLD CONGRESS 2003, Göteborg, Sweden, June 14-19, 2003

\section{APPENDIX C}

Non-Imaging Devices for Uniform Irradiance on Planar Surfaces for Parabolic Concentrators, D. Dye and B. Wood, University of Nevada, Reno, Proceedings of the American Solar Energy Society 2003 Annual Conference, Austin, TX, June 16-25, 200 


\title{
Infrared Transmission Efficiency of Refractive and Reflective Non- Imaging Devices for a Full-Spectrum Solar Energy System
}

\author{
Dan Dye ${ }^{*}$ and Byard Wood \\ Mechanical Engineering, Mail Stop 312, University of Nevada, Reno \\ Reno, NV 89557
}

\begin{abstract}
A solar collector/receiver for a full-spectrum solar energy system is being designed by a research team lead by Oak Ridge National Laboratory and the University of Nevada, Reno, ${ }^{1,2}$. This solar energy system is unique in that it utilizes the majority of the solar spectrum. The collector/receiver is a modified Cassegrain system that uses a large parabolic mirror and a secondary mirror comprised of multiple planar segments. The secondary mirror segments are coated with a spectrally selective cold mirror coating that lets the infrared (IR) energy pass through while reflecting the visible light.

The focus of this paper is on determining whether a refractive or a reflective non-imaging (NI) tube will produce the most uniform irradiance of the IR energy on the thermophotovoltaic (TPV) array. It has been shown that a rectangular NI tube will work well for the prototype system ${ }^{3}$. The results herein show that a reflective NI tube will perform best for this system, with a short length, minimum/maximum flux ratio of 0.94 and power output of $37 \mathrm{~W}$. It is also shown that a square shaped TPV array can increase the optical efficiency by $9 \%$ and the overall system efficiency by $2 \%$.
\end{abstract}

Keywords: non-imaging device; thermophotovoltaic; infrared; full-spectrum; solar energy

\section{INTRODUCTION}

A full-spectrum solar energy system combining daylighting and electric power generation is under development. The concept for this system is shown in Figure 1. The visible portion of the solar spectrum is separated from the IR and concentrated for transmittance of the daylight via fiber optics to hybrid luminaries. The IR spectrum is concentrated and directed onto a TPV array behind the secondary mirror for electric power generation. The IR energy that passes through the secondary mirror will be directed to the TPV array shown in Figure 2. Work has been performed to determine the optimum shape of a NI device to homogenize the IR flux concentrated by the primary parabolic mirror incident on the gallium antimonide $(\mathrm{GaSb}) \mathrm{TPV}$ array. The results of that research show that a rectangular tube would perform the best as the NI device. In general, square NI tubes show the most promise ${ }^{4}$, but due to the silhouette of the current TPV array, other cross sections have been investigated. The next step is to determine if a total internal reflecting (TIR) or a hollow internal reflecting (HIR) system would work the best for this prototype system. The average incident angle at the focal plane is approximately 49 degrees, so reflection losses are expected at the entrance of the TIR tube. The HIR tube will not have the entrance aperture losses, but the advantage of the refractive TIR system is that the average incident angle at the exit aperture will decrease to about 31 degrees, while the reflective HIR system will retain the higher angles.

To determine which type of NI device would perform the best for the benchmark TPV array, two different configurations have been investigated: an HIR and a TIR system with rectangular cross-sectional shape. The results of the detailed analysis have been used to determine which system has the highest energy transfer efficiency. A second generation TPV array is suggested. This array has a close to square silhouette and the HIR and TIR NI tubes will be used to compare this system to the benchmark, or first generation, system. It is expected that the second generation system will have a higher efficiency from the NI optics entrance to exit aperture due to more useable area

\footnotetext{
* dye@unr.edu; phone 775 784-6735; fax 775 784-1701; energy.unr.edu
} 
at the exit aperture. But, compared to the IR losses at the secondary mirror, this gain in NI optics efficiency may be negligible.

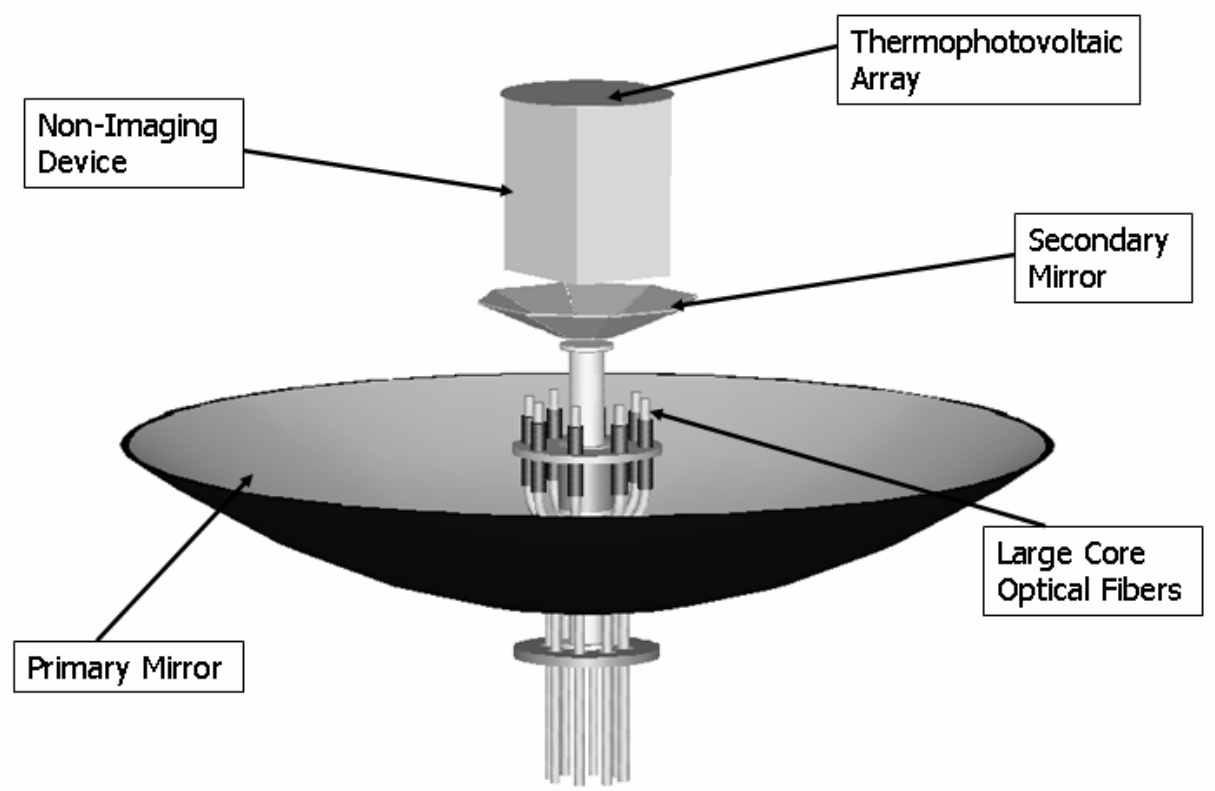

Figure 1: Full-Spectrum Solar Energy System

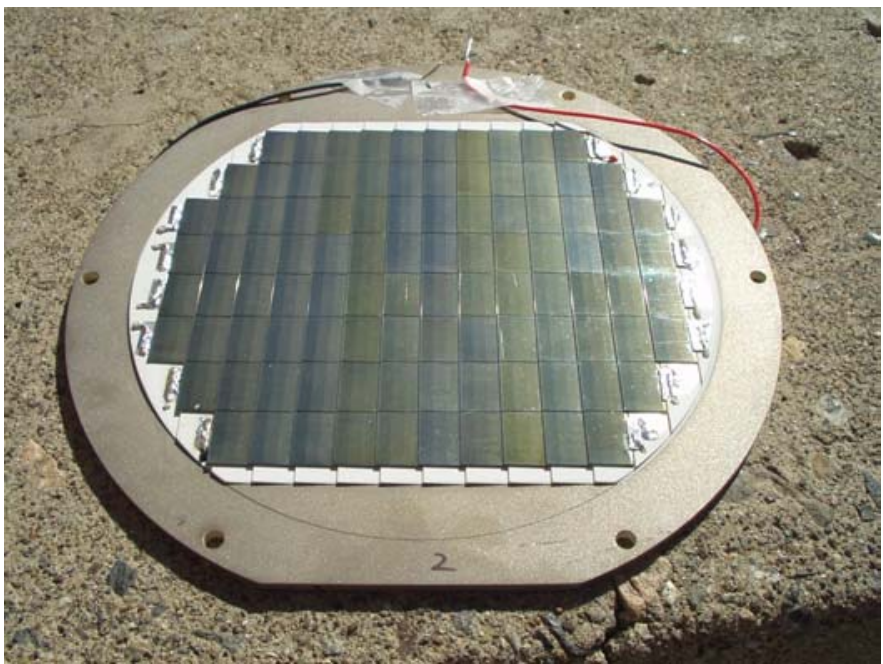

Figure 2: 100-Cell GaSb TPV Array

For more efficient energy transfer, a square-shaped TPV array is suggested. Based on the test data from the original TPV array ${ }^{5}$, each cell in the array has a voltage at the maximum power point of $\mathrm{V}_{\max }=0.345 \mathrm{~V}$ and an open circuit voltage of $\mathrm{V}_{\mathrm{oc}}=0.477 \mathrm{~V}$. The dimensions of each cell are approximately $16.33 \mathrm{~mm} \times 10.85 \mathrm{~mm}$. Using this data, a possible array could have 96 cells, which will have $\mathrm{V}_{\mathrm{oc}}=45.8 \mathrm{~V}, \mathrm{~V}_{\max }=33.1 \mathrm{~V}$, and outside dimensions of $13 \mathrm{~cm} \mathrm{x}$ $13 \mathrm{~cm}$. This array has been used in the analysis as a possible second generation TPV array. Figure 3 shows the comparison of the 100 cell array and the proposed 96 cell array. This second generation array will reduce the unused area at the exit aperture of the NI tube, as well as allow for the use of a square NI tube. This should produce a more homogenized flux across the array surface as well as increase the maximum power output of the array. 


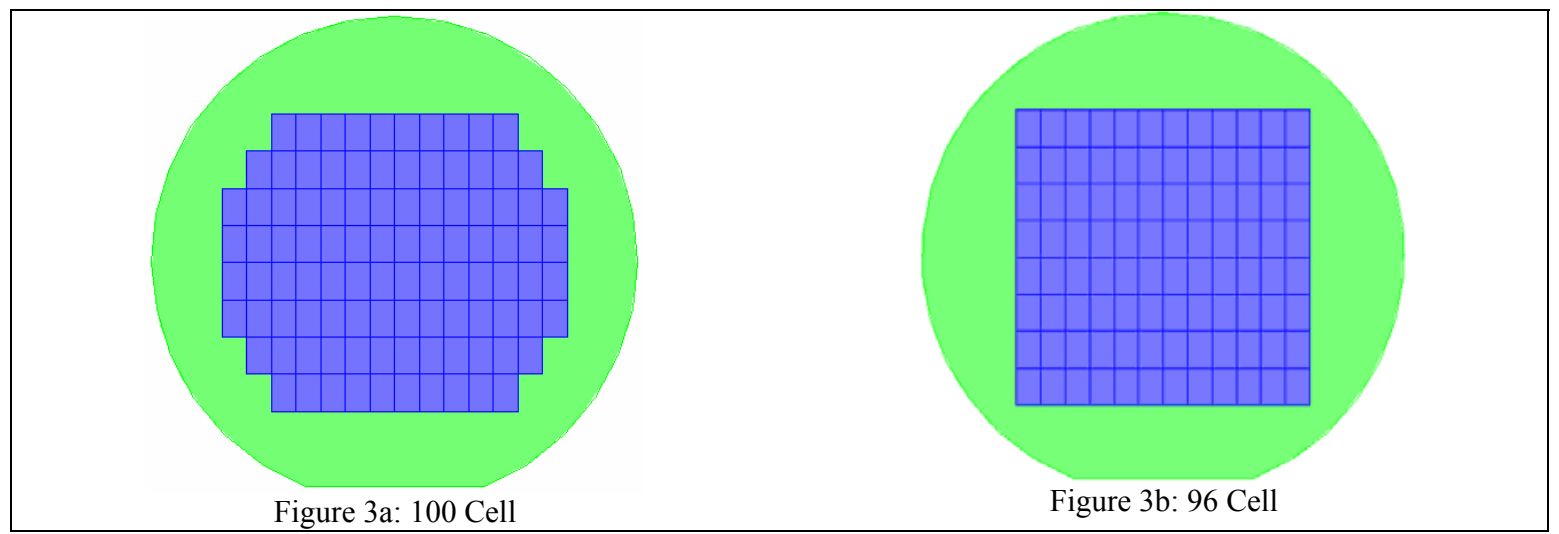

Figure 3: 100 cell and proposed 96 cell TPV arrays

\section{METHODOLOGY}

Solid models of the collector/receiver system and all optical components were built within TracePro version 3.0. The system was modeled with the surface properties of the primary and secondary mirrors, as shown in Figures 4 and 5. For the refractive TIR NI tube, silica was used as the material, and for the HIR NI tube, an average wall reflectivity of $97 \%$ was used. For the ray source of the model, the 0.7 to $1.8 \mu \mathrm{m}$ spectrum of Air Mass 1.5 was used, with approximately 12.5 million rays per square meter traced.

Primary Mirror Reflectivity

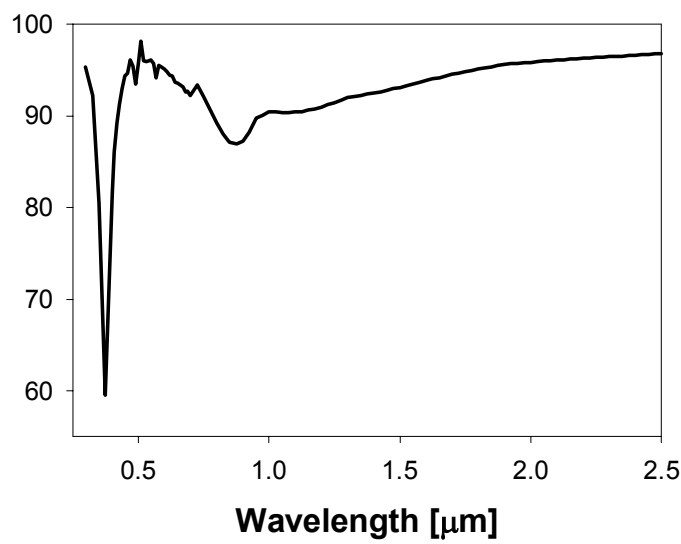

Figure 4. Primary Parabolic Mirror Spectral Response
Secondary Mirror Transmissivity

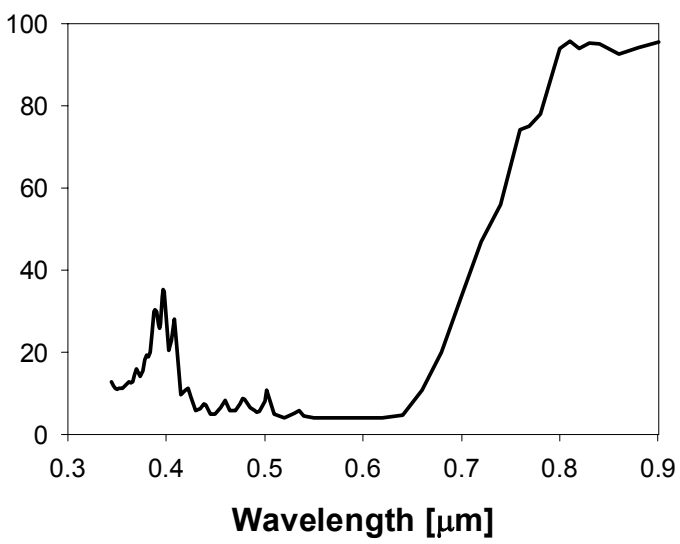

Figure 5. Secondary Mirror Spectral Response

Once the system model is built, the NI tube is placed with the entrance aperture at the focal point of the primary mirror. The TPV array is then placed near the focal point in the NI tube, moved incrementally down the NI tube away from the focal point, and a TracePro file is generated for each location. A Scheme code is written which runs TracePro through the batch of files and the results are saved for post-processing in Excel 2002. Once the data is in Excel, it can be processed to provide useful information about the flux distribution across the array surface and the surfaces of other system components, as well as the angular distribution of the incident rays on a surface. 


\section{DATA}

The data generated by TracePro can be used to produce figures that show how the minimum cell flux, homogeneity of the flux, and the maximum array output vary with the NI tube length. The angular distribution of the rays on the TPV array can also be collected and processed with a statistical package. Figure 6 shows a histogram of the incident angles at the focal plane. The angles normal to the focal plane of the parabolic mirror are conserved inside the HIR tube, so this distribution is the same for the entrance and exit apertures of the HIR tube. Figure 7 shows a histogram of the incident angles at the exit aperture of the TIR tube. These rays have been refracted, and some of the steeper rays have been lost due to Fresnel losses, so the distribution is quite a bit different. As shown, the rays inside the HIR tube range from 22 to 69 degrees, while in the TIR tube they range from about 14.5 to 40 degrees.

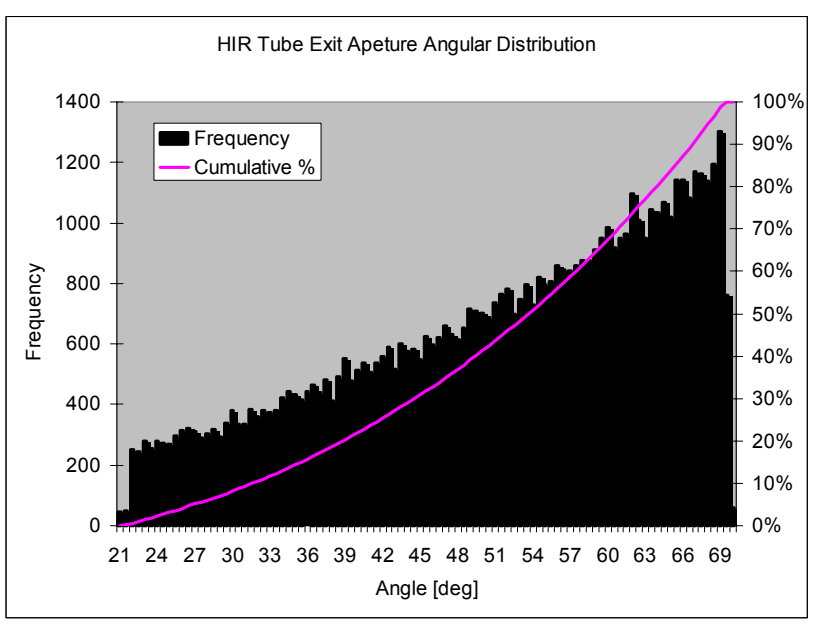

Figure 6: HIR Tube Angular Distribution

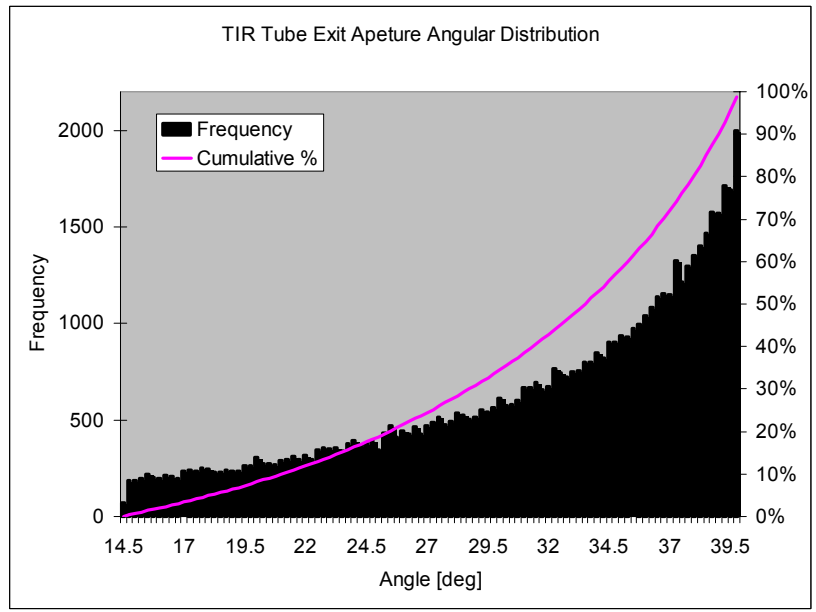

Figure 7: TIR Tube Angular Distribution

Figures 8 and 9 show the minimum to maximum flux ratio versus the distance of the array from the focal point, or the NI tube length. These figures show how well the flux has been homogenized. Due to the fact that the rays entering the TIR tube are refracted and act as though the system had a longer f/D ratio, the system requires a significantly longer NI tube length to homogenize the flux.

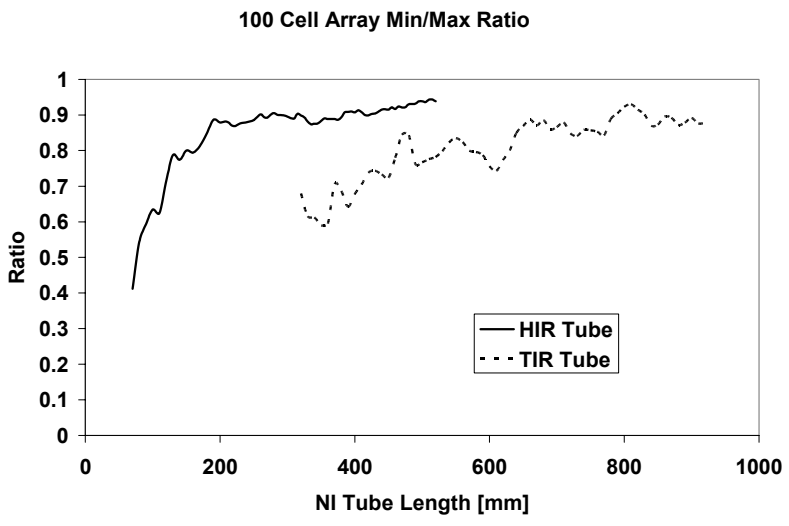

Figure 8: 100 Cell Array Min/Max Flux Ratio

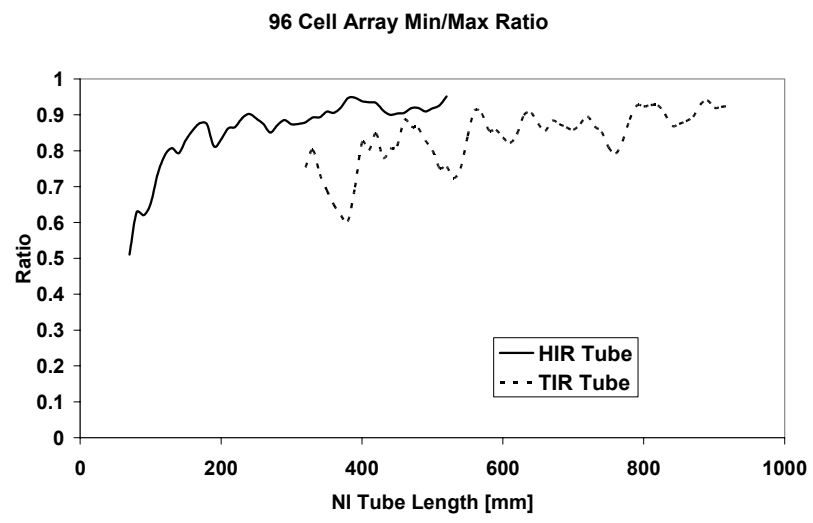

Figure 9: 96 Cell Array Min/Max Flux Ratio

Figures 10 and 11 show the maximum power output from the TPV array. The output of the TPV array is driven by the minimum cell flux on the array. The maximum power output is then simply the minimum flux multiplied by the 


\section{APPENDIX A}

array area and then multiplied by the efficiency of the GaSb cells, which is estimated to be $18 \%$. Again, the HIR tube produces results with a shorter tube length than the TIR tube. After a maximum is reached, the HIR tube shows a decrease in the power output as the length is increased, due to reflective losses inside the tube, while the TIR tube does not show a significant decrease. This is for a perfect TIR tube though. Dirt, imperfections, and surface roughness will obviously decrease the transmission of the TIR tube with increased length as well.

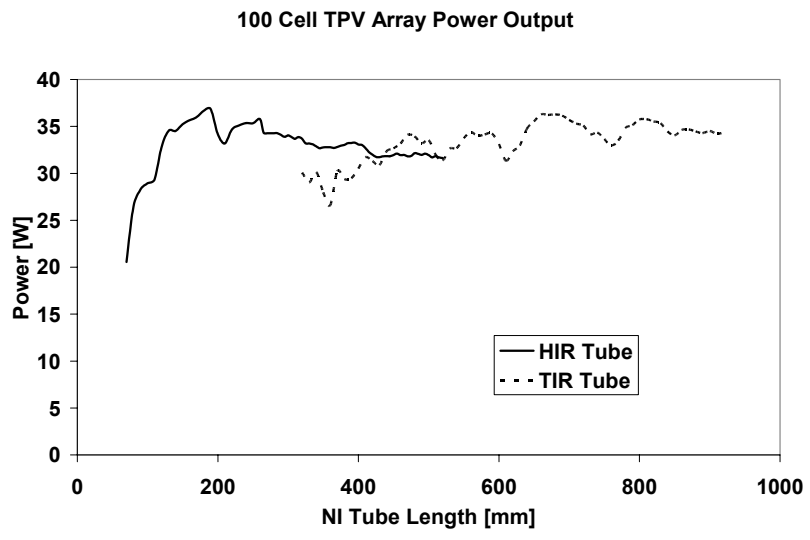

Figure 10: 100 Cell Array Power Generation

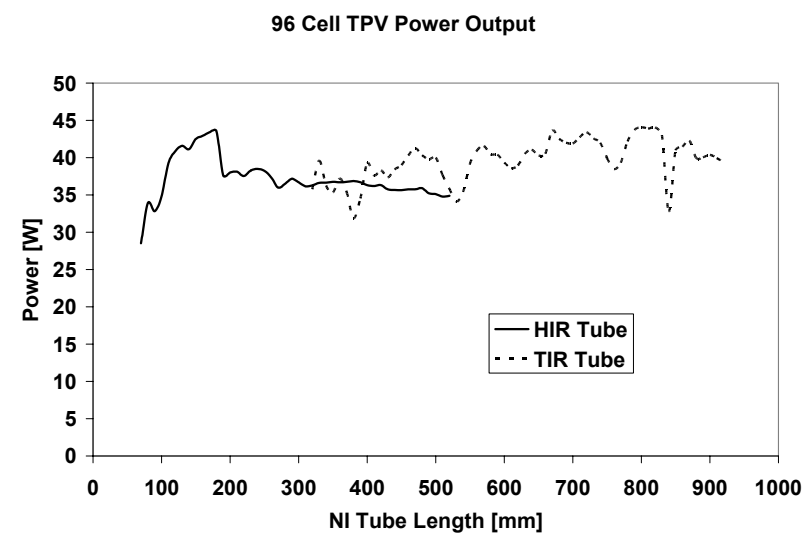

Figure 11: 96 Cell Array Power Generation

\section{RESULTS}

The results from the raytrace analysis are presented below in Tables 1 and 2. For both the 96 cell and 100 cell arrays, the outputs from the two different NI tubes are comparable. From Air Mass 1.5, there is approximately 395 $\mathrm{W} / \mathrm{m}^{2} \mathrm{IR}$ energy available in the spectrum used for this analysis, and the benchmark system collects about $404 \mathrm{~W}$. The predicted outputs from the 100 cell array are $37 \mathrm{~W}$ from the HIR tube and $36 \mathrm{~W}$ from the TIR tube. The predicted outputs from the 96 cell array are $44 \mathrm{~W}$ from both the TIR and HIR tubes. This is an increase in power production of almost $19 \%$ by simply changing the shape of the TPV array. The optical system efficiency of the 100 cell array systems is about $51 \%$, and for the 96 cell array systems it is about $60 \%$. With the IR energy conversion efficiency of the TPV cells accounted for, the overall system efficiency for the 100 cell and 96 cell arrays are $9 \%$ and $11 \%$, respectively.

Table 1: Comparison Between HIR and TIR Tubes for the 100 Cell TPV Array

\begin{tabular}{|c|c|c|}
\hline \multicolumn{3}{|c|}{100 Cell TPV Array } \\
\hline & HIR Tube & TIR Tube \\
\hline Peak min/max ratio & 0.94 & 0.93 \\
\hline Distance from focal point [mm] & 515 & 810 \\
\hline Peak Minimum Cell Watts & 2.05 & 2.02 \\
\hline Distance from focal point [mm] & 190 & 660 \\
\hline Maximum available power ${ }^{1}[\mathrm{~W}]$ & 205 & 202 \\
\hline Power Transfer Efficiency & 51 & 50 \\
\hline Maximum power output ${ }^{2}[\mathrm{~W}]$ & 37 & 36 \\
\hline Overall System Efficiency [\%] & 9 & 9 \\
\hline
\end{tabular}

${ }^{1}$ Minimum cell power multiplied by the number of cells

${ }^{2}$ Maximum power available multiplied by an efficiency of $18 \%$

Table 2: Comparison Between HIR and TIR Tubes for the 96 Cell TPV Array 


\begin{tabular}{|c|c|c|}
\hline \multicolumn{3}{|c|}{96 Cell TPV Array } \\
\hline & "HIR Tube & TIR Tube \\
\hline Peak min/avg ratio & 0.95 & 0.94 \\
\hline Distance from focal point [mm] & 480 & 900 \\
\hline Peak Minimum Cell Watts & 2.52 & 2.55 \\
\hline Distance from focal point [mm] & 180 & 800 \\
\hline Maximum available power ${ }^{1}[\mathrm{~W}]$ & 242 & 245 \\
\hline Power Transfer Efficiency & 60 & 61 \\
\hline Maximum power output $^{2}[\mathrm{~W}]$ & 44 & 44 \\
\hline Overall System Efficiency [\%] & 11 & 11 \\
\hline
\end{tabular}

${ }^{1}$ Minimum cell power multiplied by the number of cells

${ }^{2}$ Maximum power available multiplied by an efficiency of $18 \%$

\section{CONCLUSIONS}

For the current TPV array, the structure of the array's cells essentially necessitates the use of an HIR tube. The cells are stacked in a shingle-fashion, thus there is not a planar front surface. A TIR tube induces losses at both the entrance and exit apertures, as well as being longer and probably more expensive than the HIR tube. These factors lead to the decision to use an HIR tube. Tests must be performed on the GaSb TPV cells in order to determine their response to the angle of incidence of the incoming rays. How the performance decreases with incident angle will play a role in the development of the full-spectrum collector/receiver.

An HIR tube with a length of $190 \mathrm{~mm}$ will produce the maximum power output for the 100 cell array. For the 96 cell array, a tube length of $180 \mathrm{~mm}$ is required. It is noted that the best $\mathrm{min} / \mathrm{max}$ flux ratio is achieved at a substantially longer tube length in both cases; $515 \mathrm{~mm}$ and $480 \mathrm{~mm}$ respectively.

A NI device might be used in the full-spectrum solar energy system in a location other than in front of the TPV array. If thermal management issues are overcome, the fiber optic cables might be centered in a bundle instead of arranged around the axis in an array of individual fibers. If the fibers are put into a bundle, this could possibly relax the stringent tracking and alignment requirements of the system. If a bundle is used, then a NI device could be beneficial because the individual fibers in the bundle would receive a more uniform flux, thus the output of all fibers pulled from the bundle would be nearly equal. Simple, preliminary tests show that the min/max ratio with a nonimaging device in front of a fiber bundle can be on the order of 0.9 , as expected. With a circular tube in front of the fibers, instead of a square-shaped NI tube, the min/max ratio could be very poor. Work will be performed to determine whether this is of concern.

\section{ACKNOWLEDGMENTS}

This project is funded in part by DOE Cooperative Agreement DE-FC26-01NT41164. Thanks are due to the Energy Systems Laboratory at the University of Nevada, Reno, Oak Ridge National Laboratory, and all of the Adaptive Full-Spectrum Solar Energy Systems team members.

\section{REFERENCES}

1. Wood, B.D., Muhs, J., “Adaptive Full-Spectrum Solar Energy Systems”, NETL Report \# 41164R02, 8/31/2002

2. J. Muhs, "Design and Analysis of Hybrid Solar Lighting and Full-Spectrum Solar Energy Systems," American Solar Energy Society, SOLAR2000 


\section{APPENDIX A}

3. Dye, D., Wood, B.D., Fraas, L., and Muhs, J., "Optical Design of an Infrared Non-Imaging Device for a FullSpectrum Solar Energy System," Proceedings of the ASME International Solar Energy Society Conference, Hawaii, 2003

4. O'Gallagher, J.J, Winston, R. and Gee, R., "NonImaging Solar Concentrator with Near Uniform Irradiance for Photovoltaic Arrays," Nonimaging Optics: Maximum Efficiency Light Transfer VI, Proceedings of SPIE Vol. 4446 (2001)

5. L.M. Fraas, W.E. Daniels, J. Muhs, "Infrared Photovoltaics for Combined Solar Lighting and Electricity for Buildings," Proceedings of 17th European Photovoltaic Solar Energy Conference, (2001) 


\title{
APPENDIX B
}

\section{A TRNSYS MODEL OF A FULL SPECTRUM HYBRID LIGHTING SYSTEM}

\author{
G.O. Schlegel, S.A. Klein, W.A. Beckman \\ Solar Energy Laboratory \\ 1500 Engineering Drive, Madison, WI 53705 USA \\ Email: beckman@engr.wisc.edu \\ B.D. Wood \\ Department of Mechanical Engineering, University of Nevada \\ Reno, Nevada, USA. \\ J.D. Muhs \\ Oak Ridge National Laboratory \\ Oak Ridge, Tennessee, USA
}

\begin{abstract}
Hybrid lighting is a new approach to lighting that integrates light from natural and electric sources. A two-axis tracking concentrator collects beam radiation which is reflected onto a mirror that divides the solar radiation into infrared and visible spectra. The visible light is distributed through optical fibers and combined with fluorescent lighting in specially designed luminaires. The infrared portion of the spectrum is used to generate electricity using a thermal photovoltaic array. A simulation of a hybrid lighting system has been created using the TRNSYS transient thermal simulation program. The simulation incorporates the spectral properties of the hybrid lighting components as well as the spectral distribution of the incoming solar radiation that is based upon output from the SMARTS atmospheric transmittance model. An office building model is coupled with the hybrid lighting simulation to predict the annual energy impact upon lighting, heating, and cooling loads. Simulations were performed in six locations within the United States. Hybrid lighting systems performed best in Honolulu, HI and Tucson, AZ justifying system capital costs of $\$ 2800$ and $\$ 2050$, respectively, based on a 10 year payback period.
\end{abstract}

\section{INTRODUCTION}

Hybrid lighting is a new solar lighting technology that separates collected solar radiation into visible and thermal portions. The visible portion is used to light buildings and the infrared (IR) portion is used to generate electricity with thermal photovoltaic cells. The technology is currently under development in the United States by a design team comprised of members of industry and academia and led by Oak Ridge National Laboratory. The purpose of this particular study is to evaluate the feasibility and economics of the technology

The hybrid lighting technology consists of a two-axis, concentrating collector that gathers direct normal solar radiation throughout the day. The direct normal solar radiation is reflected onto a secondary element which divides the solar radiation into the visible and infrared spectrums. The visible light is reflected off of the secondary element and focused into large core optical fibers which transport the light into a space. The infrared energy is transmitted through the secondary element and focused onto a thermal photovoltaic array which uses the energy to generate electricity. There are two major benefits from hybrid lighting. The first benefit is the reduction in purchased electricity needed to light the building, and the second benefit is a reduced cooling load due to the high efficacy of natural light.

A model of a hybrid lighting system was created in TRNSYS (Klein et al., 2000). The model consists of two major components; the building component and the hybrid lighting component. The TRNSYS type 56 building component was configured to simulate a large multi-use environment such as a retail or office space. The hybrid lighting component model uses the incoming beam radiation and spectral properties of the hybrid lighting system to determine the light and electricity benefits produced. The light 'produced' by the hybrid lighting component is fed back into the building model to calculate the impacts the hybrid lighting technology has upon building loads.

An economic model was implemented into the TRNSYS simulation based on the $P_{1}, P_{2}$ methodology (Duffie and Beckman, 1991). Local utility rate schedules are used to convert the hybrid lighting impacts upon the building lighting, heating, and cooling loads into dollars. Using the $P_{1}, P_{2}$ economic model in conjunction with the energy savings predicted by TRNSYS, a break-even capital cost can be determined for the hybrid lighting system. 


\section{APPENDIX B}

\section{HYBRID LIGHTING COMPONENTS}

As shown in Figure 1, the radiation collection system, the light distribution system, the controls, and the luminaires are the four major components of a hybrid lighting system. The collection system is composed of a concentrating solar collector that tracks the sun and gathers solar beam radiation. The radiation is filtered into two types; the visible and the IR radiation. The IR radiation could be used for water heating or other purposes but in this system it is used for electricity generation with a thermal photovoltaic array. The visible radiation is channeled through the light transmission system, to specially configured luminaires, and into the lighted space.

\subsection{Concentrating Collector}

The concentrating collector is composed of a concentrator in the form of a circular parabolic mirror and a receiver onto which the radiation is focused. The collector gathers the terrestrial radiation and increases the power density of the light by focusing it onto the smaller area of the receiver. Materials used for the concentrator have a high average reflectivity of approximately 0.95 . Reflection losses and losses due to the secondary element obstruction determine the output of the concentrating collector.

\subsection{Secondary Element - Cold Mirror}

The secondary element lies near the focal point of the concentrating collector. It is assumed that all of the solar radiation reflected from the dish strikes the secondary element. The secondary element is comprised of an eight faceted "cold" mirror. The "cold" mirror allows infrared energy to be transmitted while the visible energy is reflected. The spectral properties of the cold mirror are not perfect and some of the solar radiation will be lost in the process of being reflected, transmitted, or absorbed. As shown in Figure 2, the cold mirror is especially poor reflector at the transition between the visible spectrum and infrared spectrum. The low reflectance in the transition region is relatively insignificant due to the spectral sensitivity of the human eye (1924 Standard CIE Visibility Curve). The eye does not respond very well to wavelengths approaching $0.78 \mu \mathrm{m}$, so the reflectance losses at long visible wavelengths are not as significant as they appear to be. The average reflectance of the cold mirror in the visible spectrum is $93 \%$ while the average transmittance in the IR spectrum is $96 \%$.

\subsection{Thermal Photovoltaic Array}

The thermal photovoltaic (TPV) array is a Gallium Antimonide (GaSb) device which is sensitive in the near infrared spectrum. The overall benefit of including the TPV array in the system is that energy in the near infrared spectrum, which would otherwise be wasted, can be used to generate electricity. A typical silicon (Si) photovoltaic cell would not be effective in this application since its sensitivity is high in the visible spectrum. The thermal photovoltaic voltaic array is made up of 100 cells wired in series over an area of approximately $180 \mathrm{~cm}^{2}$. Due to the series configuration of the TPV array, the array performance will be limited by the cell which receives the least amount of radiation. A non-imaging optical device is being developed to provide a uniform level of radiation incident on the surface of the array. Current simulations performed at the University of Nevada-Reno indicate that a rectangular tube with a wall reflectance of $95 \%$ can increase the uniformity of the radiation incident upon the surface of the TPV array (Dye et al., 2003). The study indicates the flux variation to be $18.7 \%(+7.9 \%,-10.8 \%)$ when using a rectangular tube approximately 25 inches in length. This is an improvement from a flux variation of $2525 \%$ at the focal point of the concentrator. Additional losses will occur due to geometric differences between the array and the optical device. The model used in the simulations includes a uniform $95 \%$ reflection loss from the walls of the optical device and an additional $20 \%$ loss due to differences in the geometry of the optical device and the TPV array. The non-uniform flux distribution limits the output of the array so an additional $10.8 \%$ reduction in incident IR radiation is included in the model to account for the variation predicted by Dye.

\subsection{Light Distribution System}

The light transmission system is composed of flexible, large core optical fibers. Visible light reflected from the secondary element is focused into these fibers and transmitted to locations in the building where it is needed. The current material being evaluated is a high-luminance light fiber. The light fiber is made of polymethacrylate which is flexible and resistant to fatigue, elongation, and vibration. The spectral attenuation of the fiber is very low except for an absorption band near $635 \mathrm{~nm}$ (see Figure 2). Since we are only dealing with the visible portion of the spectrum and the quantity of visible light is important, the standard CIE visibility curve must be included to calculate the transmittance of the optical fibers. When the attenuation data are weighted by the response of the human eye, the transmission characteristics in the middle of the spectrum $(555 \mathrm{~nm})$ become more important, and the spike near the long wavelength portion of the spectrum is not much of a factor. 


\section{APPENDIX B}

According to Tekelioglu and Wood, (2003) the optical fiber temperature will reach a critical point at the fiber inlet unless some type of IR filtering is used. Tekelioglu evaluated a number of different filtering and cooling methods and concluded that two techniques could be economical and effective. One technique involves the use of an additional IR filter to reflect any IR radiation before it enters the light fiber. However, the filter transmittance of $90 \%$ adds significant losses to the light production of the hybrid lighting system. The second technique uses $14 \mathrm{~mm}$ thick fused quartz glass to filter out any undesirable IR radiation. The fused quartz glass method offers an economical and effective solution to overheating at the fiber entrance. Losses due to the coupling of the quartz and optical fiber are estimated at $3 \%$ (Maxey et al., 2003) and visible transmission losses through the quartz are estimated at $2 \%$.

Another important aspect of the transmission system is the effect the light fiber has upon the color of the light output from the fiber. In a typical installation the light fibers are run through ceilings and walls to get to the appropriate location. The route will undoubtedly contain many bends. Bending the light fiber causes increased attenuation and a shift in the color of the light. Oak Ridge National Laboratory (ORNL) has developed a chromaticity model to predict the color change of the light depending on the length of light fiber, number of bends, and bend radius (Earl and Muhs, 2003). The effect of additional attenuation losses due to bending has not been included in the model presented here. This hybrid lighting model uses the spectral attenuation data, a uniform entrance loss, and average fiber length to model the transmission losses.

\subsection{Luminaires and Controls}

Control systems will have to be created to ensure that the combination of hybrid solar and electrical lighting maintains a uniform lighting level. A control system consisting of light sensors coupled with dimmable electronic ballasts can adjust the artificial illumination levels within the building during the presence of natural light. Unfortunately the efficacy of dimmable fluorescent lighting decreases with decreasing load fraction (NLPIP, 1999). Other control scenarios involve using constant efficacy fluorescent lighting and controlling the illumination by turning the lights on and off in stages. Problems with the staging control strategy include lighting uniformity and illumination level variation. A control system combining the dimmable fluorescent lighting with a staging control strategy may be the best solution.

The hybrid lighting systems have a combination of electrical and natural light sources in each luminaire. Each luminaire needs to be able to produce a uniform source of light using electrical light, natural light, or both. Two designs have been developed that can be integrated into existing or new construction. An end light design 'plugs' the light fiber into a hemispherical diffuser much like recessed incandescent light fixtures. A side-light design utilizes a cylindrical diffuser, similar in shape to a fluorescent light bulb, to distribute the light evenly. Both designs are currently being developed to improve the light distribution and efficiency. Sufficient spectral data are not currently available to predict the efficiency of the different luminaire designs. Preliminary experimental data from ORNL reported a $58.4 \%$ efficiency of the side emitting rod luminaires (Earl et al., 2003). It is estimated that nearly $20 \%$ of the losses are due to optical fiber coupling losses which have since been addressed by Maxey (Maxey et al., 2003).

\section{THE HYBRID LIGHTING MODEL}

The hybrid lighting simulation was developed to utilize either spectral (narrow band) or average (wide band) data to model radiation and hybrid lighting component properties. The TRNSYS model consists of one new subroutine, type 292, that provides all of the programming for both the narrow-band and wide-band hybrid lighting models. The wide-band model simulates a hybrid lighting system using average spectral properties of the components of the system, while the narrow-band model uses spectral properties input at $5 \mathrm{~nm}$ bandwidths. The narrow-band model utilizes spectral data for the concentrator, the secondary element, the TPV, the optical fibers, and the human eye. The solar irradiance model embedded within the narrow-band subroutine predicts the spectral distribution of direct normal solar radiation at $5 \mathrm{~nm}$ bandwidths based upon the output of SMARTS version 2.91 (Gueymard, 2000). Both the wide-band and the narrow band models predict the potential savings of a hybrid lighting system in terms of energy and dollars.

\subsection{The Building Model}

The building component is modeled using the TRNSYS type 56 multi-zone building model. Type 56 is designed to provide detailed thermal models of buildings. The model consists of two windowless $2500 \mathrm{~m}^{2}$ zones. One zone 


\section{APPENDIX B}

uses standard fluorescent lighting and the other zone uses a hybrid lighting system. Schedules in the two zones simulate the heating, cooling, and ventilation of a typical mixed use environment. Additional gains in the model account for the people, computers, and lights in the building. Cooling in the building is supplied using a chiller and heating loads are met through the combustion of natural gas. Using time-of-day rate schedules, energy costs can be calculated for the two zones of the building model with the difference representing the energy savings due to the hybrid lighting system.

\section{SIMULATION RESULTS}

Annual simulations were run to evaluate a hybrid lighting system in six different climate regions within the United States (U.S.). Reno, NV and Tucson, AZ, were used to represent mountain and desert climates. Seattle, WA, was chosen to show the effectiveness of the technology in the Pacific Northwest. Madison, WI was chosen to represent the Midwestern U.S., and Atlanta, GA was used to represent the Eastern U.S. An additional simulation was run for Honolulu, HI due to the large amount of sunshine and high electricity prices in Hawaii. The results of the simulation include lighting, heating, and cooling load estimates for the building with and without the hybrid lighting system. The annual energy savings due to the hybrid lighting system can be calculated from the difference in energy loads and the generation from the TPV array. Using the annual energy savings and the $P_{1}, P_{2}$ economic methodology, the break-even capital cost of a hybrid lighting system can be determined for a particular location. The break-even capital cost is defined as the cost per module that will cause the life-cycle cost of owning and operating the hybrid lighting system over the economic analysis period to be same as the cost of operating a conventional system. If the hybrid-lighting system can be installed at a cost below the break-even capital cost, it will result in a savings over the economic analysis period. Break-even capital costs can be used both as a design goal for the development team as well as a metric to measure where the technology will be most effective.

The simulations were run using the type 56 building model, the narrow-band hybrid lighting model, and TMY2 weather data for each location. The concentrator surface consisted of a highly reflective enhanced aluminum coating with an active area of $1.7 \mathrm{~m}^{2}$. The optical fibers averaged 7 meters in length with a $5 \%$ fiber entrance loss included to account for additional IR filtering. Illuminance levels in the building were set to 500 lux from 8 am to 5 pm 7 days a week, and the luminaire efficiency was assumed to be $83 \%$. Simulations were performed using both high efficacy and low efficacy lighting to show the effect of building lighting upon the hybrid lighting system performance.

\subsection{Lighting}

The lighting loads of the building with increasing numbers of hybrid lighting modules are shown in Figure 3 . The lighting load decreases linearly with increasing number of modules until the lighting system begins to saturate. At the saturation point, the hybrid lighting system produces more light than is needed on some days and thus displaces less energy per additional module. As expected, the system in Tucson, AZ performed the best and the system in Seattle, WA showed the worst performance. Although the system in Hawaii is closer to the equator the high amounts of moisture in the Hawaiian climate lead to smaller amounts of annual beam radiation than dry climates like Reno, NV and Tucson, AZ.

The system in Hawaii saturated at higher number of systems than the other locations because the lower latitude resulted in daylight hours more in phase with the building lighting hours. The fluorescent lighting in the building is operational from 8 am to $5 \mathrm{pm}$. In Hawaii the sun always rises by 8 am and sets after $5 \mathrm{pm}$, but in Reno for 2-3 months of the year the sun sets before $5 \mathrm{pm}$. During this time the hybrid lighting system cannot be used in Reno but it still can be used in Hawaii. Longer useful daylight hours in Hawaii lead to a larger number of modules before saturation when compared to an identical system located in Reno.

As expected, the lighting load with no hybrid lighting modules is higher when using a low efficient light bulb as shown in Table 1. When the number of hybrid lighting systems is increased the energy savings is greater for the set of simulations using low efficacy lighting. Although this makes the hybrid lighting systems more attractive it is more reasonable to assume that hybrid lighting systems will be accompanied by high efficiency fluorescent lighting.

Realistic controls will contribute additional losses to the hybrid lighting system. The control system simulated consisted of $85 \mathrm{~lm} / \mathrm{W}$ electronic dimmable ballasts and bulbs, photo sensors, and a 4-stage control strategy. By dividing the lights into equal stages, the lights can be maintained at full operational levels and turned off or on to 


\section{APPENDIX B}

reduce or increase the lighting load as needed. In a two stage system the lights are divided into two groups. Both groups remain on until the hybrid lighting system provides $50 \%$ of the lighting load. At this point one stage, or in this case, half, of the lights are turned off while the remaining lights stay on. The remaining half of the lights stay on until the entire load is met by the hybrid lighting system. Staging systems with more than two stages are designed in the same manner with each stage designed to meet an equal fraction of the lighting load.

The simulation results shown in Figure 3 assume perfect control. An available control system using $85 \mathrm{~lm} / \mathrm{W}$ electronic dimmable ballasts and bulbs, photo sensors, and a four stage control strategy was implemented in the model. In this control system, the photo sensors provide feedback to continuously adjust the lighting level in the building. The auxiliary fluorescent lighting system is dimmable, but reduced light output results in lower efficiency lamp performance. Staging controls were introduced to minimize the dimmable lamp and ballast inefficiencies at part-load. By dividing the lights into equal stages, the lights can be maintained at high load levels and turned off or on to reduce or increase the lighting output as needed. Using a staging control strategy allows the auxiliary lighting to operate at higher load fractions resulting in more efficient performance.

Simulations using the same physical parameters as used to generate Figure 3 but with realistic controls rather than perfect controls were performed and the results are included in Table 1. A comparison of the results included in Table 1 indicates that a well-designed control system has very little impact upon system performance. For the six locations simulated, the losses due to the controls were responsible for approximately a $5 \%$ increase in lighting load per system module. A poorly designed control system results in increased lighting loads and decreased benefits from the hybrid lighting system. Results due to the control system were seen in the building heating and cooling loads. Cooling energy savings decreased by roughly $5 \%$ for all locations while changes in heating energy savings were negligible.

3.2. $\quad$ Cooling

Simulations run in warmer climates such as Honolulu and Tucson tended to have higher annual building cooling loads than cooler climates in Seattle and Reno. Madison which has the coldest climate of the selected locations surprisingly has a higher cooling load than Reno or Seattle due to the latent cooling load in the summer. In all of the locations, the cooling load decreased with increasing hybrid lighting modules and then began to increase again as excess light was introduced into the building.

Since filtered natural light has an efficacy of approximately $200 \mathrm{~lm} / \mathrm{W}$, increasing the amount of natural light that displaces artificial light in the building should result in a reduced cooling load. Figure 4 shows the change in cooling load with additional hybrid lighting modules for the simulation using $85 \mathrm{~lm} / \mathrm{W}$ fluorescent lamps. As with the lighting load, the cooling load decreases linearly with additional systems until the building begins to saturate. As the building saturates, more light is brought into the building than is needed. This extra light, which eventually turns into heat, causes the cooling load to increase after the saturation point. From Figure 4 it is clear that sunny locations like Tucson, AZ, Reno, NV, and Honolulu, HI which already benefit from an abundance of natural daylight also have large reductions in cooling load making them ideal places for a hybrid lighting system.

\subsection{Heating}

As expected, the locations with colder climates have a higher heating load than locations with warmer climates. All of the chosen locations need some type of heating except for Hawaii.. The change in lighting gains has less of an effect on the heating load because the majority of the heating load occurs at night when the lights are off. This result is in contrast to the cooling load which typically occurs during the day when building gains and ambient temperatures are high.

Due to the range of heating loads in the various locations, Figure 5 was included to show the effect of increasing numbers of hybrid lighting modules upon the building heating load. The buildings in Madison, WI and Atlanta, GA behave as expected with a linear increase in heating load with increasing number of hybrid lighting modules. The unexpected decrease in heating load in Seattle and Tucson is due to the low annual heating demands which are dominated by night-time heating. The hybrid lighting system is only effective during daylight hours and most of the heating in these locations occurs just before sunrise. From further analysis it was found that the change in heating load was directly due to the hybrid lighting system's impact upon the cooling load during the day. The decreased cooling load from the hybrid lighting system resulted in a higher average zone temperature. As heating becomes necessary the higher zone temperature due to the hybrid lighting system results in a lower heating load. 


\section{APPENDIX B}

The climate in Reno results in both heating and cooling during the same day for much of the year. Up until about 6 modules, the building in Reno experiences a decreased heating load much like Tucson and Seattle. From 6 to 14 modules, the heating load begins to increase slightly due to an increased heating load during the day caused by the hybrid lighting system. At approximately 12-14 modules, the building begins to saturate with light and the heating load decreases due to the heat associated with the excess light.

3.4. $T P V$

The electricity produced by the TPV array is directly proportional to system size and annual beam radiation. The array in Tucson, AZ receives the most beam radiation and produces the most electricity while the array in Seattle, WA receives the least amount of beam radiation and produces the least amount of electricity. The revenue produced by the TPV array, shown in Figure 6, is a function of the annual energy production as well as the local utility rate. All energy produced by the array is assumed to be sold back to the utility at the rate the utility charges less metering, distribution, and demand fees. Electricity in Hawaii is the most expensive at an average cost of $\$ 0.184 / \mathrm{kWh}$ while the average cost of electricity in Atlanta is only $\$ 0.062 / \mathrm{kWh}$.

\subsection{Annual Savings}

The annual energy savings of each system is due to the reduction in lighting and cooling loads, the heating load impact, and the electrical energy produced by the TPV array. The energy savings is converted into dollars using rate schedules from utilities near the simulated locations. Time-of-use commercial rates were used for electricity costs and natural gas costs were based on fixed commercial rates. Figure 7 shows the annual savings for the hybrid lighting systems using perfect controls. Due to the high cost of energy, a hybrid lighting system saved the most money in Honolulu, while inexpensive energy in Atlanta resulted in low savings. The annual savings curves exhibit similar shapes with a constant energy savings per additional module until each system begins to saturate the building with light. As the system saturates the building, the cost benefit of the hybrid lighting technology decreases.

The dimmable fluorescent control system with staging affected the annual savings as shown in Figure 8. The maximum annual savings occurs just as the systems begin to saturate at a system size of 12 - 14 modules. The difference between the shape of the curves in Figure 7 and Figure 8 is due to the efficiency of dimmable ballasts at part load. The curves in Figure 7 assume that the fluorescent lighting systems can be operated at part load without any losses i.e., perfect control. In Figure 8 the fluorescent lighting operates at a lower efficiency due to losses from the dimmable lights and controls. The annual savings peaks when the hybrid lighting system can nearly meet the entire building lighting load.

Using Honolulu, HI as an example, Figure 9 shows how simulations can be used as a tool to evaluate different components of the hybrid lighting system and building. The upper most line shows the effect of fluorescent lamp efficacy on annual savings. By increasing the efficiency of the fluorescent lamp from $63 \mathrm{~lm} / \mathrm{W}$ to $85 \mathrm{~lm} / \mathrm{W}$, the peak annual energy savings drops from $\$ 667$ to $\$ 483$. This result shows the importance of establishing the correct baseline building technology. The value that the TPV array adds to the total system can be calculated by removing its contribution to the annual savings. The difference between the two curves is the money saved due to the TPV. Assuming that research time and money could be used to increase the luminaire efficiency from $83 \%$ to $95 \%$, the increased efficiency would lead to $\$ 68$ saved each year. Similar arguments can be made regarding the value associated with different control systems. Applying an economic analysis to the annual savings can produce a break-even figure for the cost of the TPV, the more efficient luminaire, an alternative a control system, etc.

\subsection{Economic Analysis}

The hybrid lighting model uses the $P_{1}, P_{2}$ economic method to calculate the break-even capital cost (BECC) of a hybrid lighting system. The BECC was chosen due to the nature of the economic indicator. At this point in the design stage, realistic component prices are not available for determining economic parameters such as years to payback, life cycle savings, or return on investment. Instead the BECC was calculated to be used as a price target where the energy savings predicted by the TRNSYS model will economically compensate for the system components. The BECC, based on the $P_{1}, P_{2}$ economic method, condenses 14 economic parameters into one which simplifies any additional economic analyses. $P_{l}$ is the ratio of the life cycle fuel cost to the first year fuel costs, and $P_{2}$ is the ratio of equipment life cycle owning and operating cost to initial equipment cost. The parameters $P_{1}$ and $P_{2}$ can be used in Equation 1 to calculate the life cycle savings (LCS) of a piece of equipment. Setting the LCS to zero Equation 1 can be re-arranged to give Equation 2, the BECC in terms of the ratio $P_{1}$ to $P_{2}$ and the annual energy 


\section{APPENDIX B}

savings in dollars from a hybrid lighting system. Using a $P_{1} / P_{2}$ ratio based upon the economic parameters listed in, the break-even capital cost of a complete hybrid lighting system can be calculated using the annual savings predicted by the TRNSYS model.

$$
\begin{aligned}
& \text { LCS }=P_{1}(\text { First Year Fuel Costs })-P_{2}(\text { Initial Equipment Cost }) \\
& \text { Break Even Capital Cost }=\frac{P_{1}}{P_{2}}(\text { First Year Fuel Costs })
\end{aligned}
$$

Table 3 shows the break-even capital cost of a hybrid lighting system for the various locations simulated. The break-even capital costs are calculated based on the maximum annual savings for each system over a 10, 20, or 30 year analysis period. For a 10 year analysis period Honolulu, HI and Tucson, AZ offer the highest break-even capital costs of and $\$ 2,800$ and $\$ 2,050$, respectively. In Madison, WI and Atlanta, GA the break-even capital costs were much less due to inexpensive electricity and lower amounts sunshine.

Table 4 contains a further economic break-down of the hybrid lighting system in Honolulu. Applying the $P_{1}, P_{2}$, economic analysis to the annual savings shown in Figure 9, the BECC can be calculated for different hybrid lighting system technologies. From this analysis the incremental BECC of the various technologies can be established and analyzed. For instance, a hybrid lighting system that is displacing light from low efficacy fluorescent lighting (63 $\mathrm{lm} / \mathrm{W}$ ) has a BECC in Honolulu of \$4069 compared to the BECC of \$2946 for a system that displaces light from high efficiency bulbs and ballasts. The difference, $\$ 1123$, is the BECC cost associated with increasing the efficacy of the building's lighting system, not a cost benefit due to the hybrid lighting system. Another example is the BECC of different control systems. The incremental BECC between dimmable fluorescents with 4 stage controls and constant efficacy fluorescents with 4 stage controls is $\$ 189$ for a 10 year analysis period. If the constant efficacy ballasts and bulbs could be replaced with dimming technology for $\$ 189 /$ module or less, the change in controls would be a sound economic decision. The BECC can be used in this manner to evaluate new developments or design cost issues based upon system energy benefits predicted by the TRNSYS hybrid lighting model.

\section{CONCLUSIONS}

Of the locations investigated, the most economic location to install a hybrid lighting system performance was Honolulu, HI with Tucson, AZ being the best location within the continental United States. Using the predicted annual savings over a ten year analysis period, the break-even capital cost of hybrid lighting modules in these locations are $\$ 2,800$ and $\$ 2,050$. Using longer economic analysis periods results in higher break-even capital costs of $\$ 3,554$ and $\$ 2,587$ for a 20 year period and $\$ 3,902$ and $\$ 2,856$ for a 30 year period. These costs represent the maximum total cost that could be invested in a hybrid lighting module without having a negative life-cycle cost over the economic period. The hybrid lighting system includes these major components: concentrating collector (active collecting area of $\left.1.7 \mathrm{~m}^{2}\right)$, two-axis tracking equipment, secondary element, TPV assembly, optical fibers $(\sim 56$ meters), luminaires (8), and controls. To manufacture, ship, and install a hybrid lighting module for less than $\$ 2,800$ will be extremely challenging.

Another factor that must be considered in these systems is the value of natural light. Studies have indicated that the benefits of natural light may include personal well-being and productivity (Fay, 2003). If the presence of natural light could be attributed to one less sick day a year, a slight improvement in employee productivity, or a higher probability that people would visit your store, then the break-even capital costs of a hybrid lighting system would increase tremendously. For instance, if the average employee with a salary of $\$ 30,000 /$ year is responsible for $\$ 60,000$ of revenue each year, and this employee's productivity increases by just $1 \%$ annually due to daylighting, then the additional revenue that the natural light indirectly provides would be $\$ 600$ per employee per year. Assume that this occurs in an office environment like the office modeled, with about 150 employees, and the annual savings and additional revenues due to the daylighting increase to $\$ 90,000$. If the physiological benefits of natural light could be included in the overall benefits received from a hybrid lighting system, the break-even capital cost of the technology would increase making it easier to economically justify. 


\section{APPENDIX B}

\section{REFERENCES}

Duffie, J.A. and Beckman, W.A., Solar Engineering of Thermal Processes, $2^{\text {nd }}$ Ed., John Wiley and Sons, 1991.

Dye, D., Wood, B.D., Fraas, L.M., Muhs, J.D., Optical Design of an Infrared Non-Imaging Device for a Full

Spectrum Solar Energy System, International Solar Energy Conference, Kohala Coast, Hawaii Island, March 15-18, 2003.

Earl, D.D., Muhs, J.D., Modeling and Evaluation of Chromatic Variations in a Hybrid Solar/Electric Lighting System, International Solar Energy Conference, Kohala Coast, Hawaii Island, March 15-18, 2003.

Earl, D.D., Maxey, C.L., Muhs, J.D., Performance of New Hybrid Solar Lighting Luminaire Design, International Solar Energy Conference, Kohala Coast, Hawaii Island, March 15-18, 2003.

Fay, C., Daylighting and Productivity, A Literature Review, International Solar Energy Conference, Kohala Coast, Hawaii Island, March 15-18, 2003.

Gueymard, C., Prediction and Performance Assessment of Mean Hourly Global Radiation, Solar Energy, Vol. 68, No. 3, March, 2000.

Maxey, L.D., Cates, M.R., Jaiswal, S.L., Efficient Optical Couplings for Fiber-Distributed Solar Lighting, International Solar Energy Conference, Kohala Coast, Hawaii Island, March 15-18, 2003 b.

National Lighting Product Information Program (NLPIP), Dimming Electronic Ballasts, Specifier Reports, available at http: \www.lrc.rpi.edu, Vol.7, Number 3, October 1999.

Klein, S.A., et al., TRNSYS, A Transient Simulation Program, Solar Energy Laboratory, University of Wisconsin Madison, USA, 2000.

Tekelioglu, M., Wood, B.D., Thermal Management of the Polymethylmethacrylate (PMMA) Core Optical Fiber for use in Hybrid Solar Lighting, International Solar Energy Conference, Kohala Coast, Hawaii Island, March 15-18, 2003. 


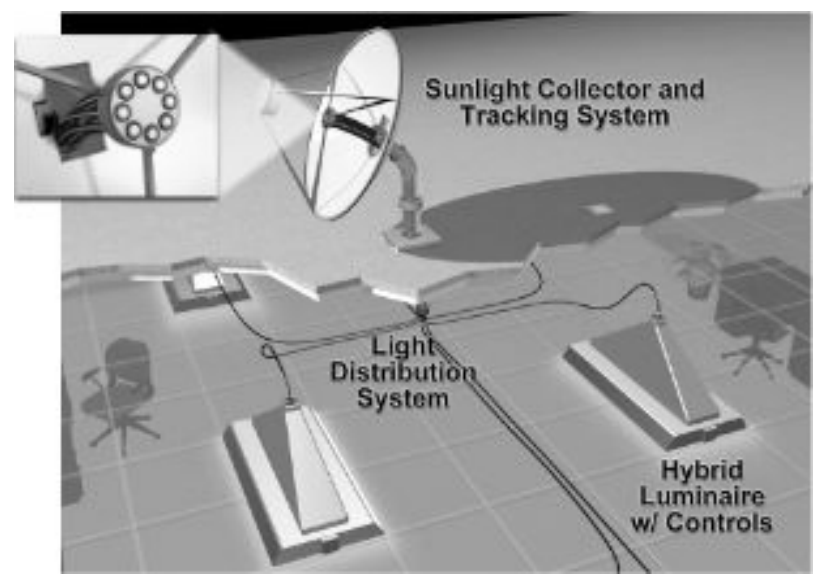

Figure 1: Hybrid lighting system

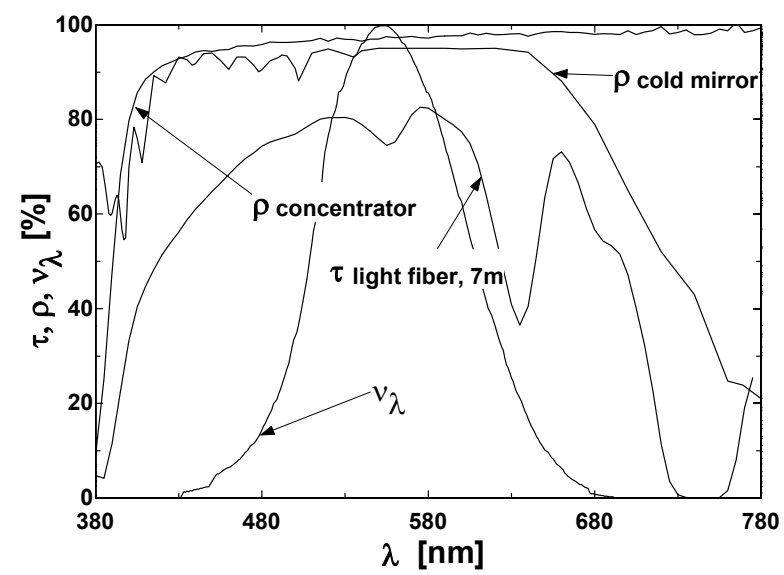

Figure 2: Hybrid Lighting Component Properties (Visible Spectrum) 


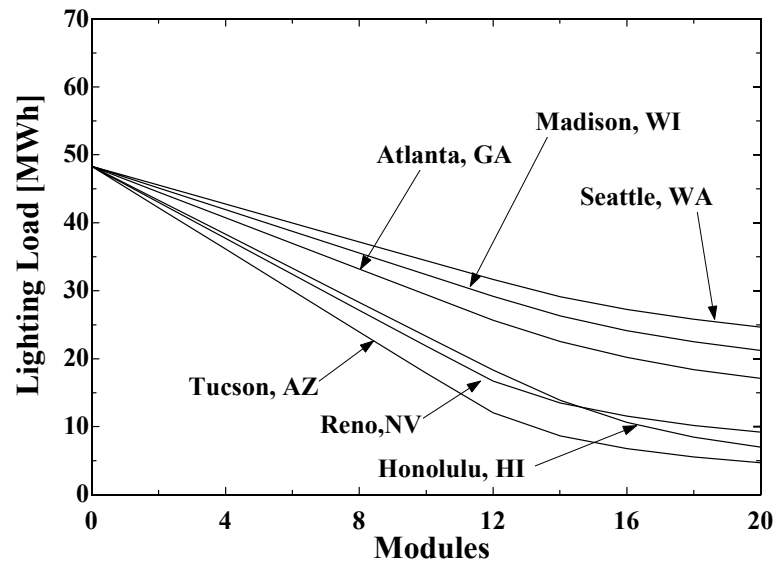

Figure 3: Lighting load, lamp efficacy $=85 \mathrm{~lm} / \mathrm{W}$

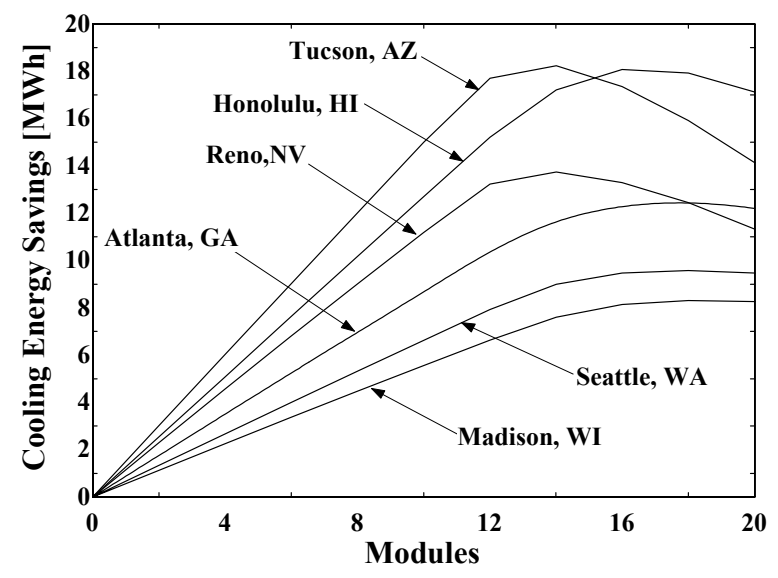

Figure 4: Cooling Energy Savings, $85 \mathrm{~lm} / \mathrm{W}$ lighting 


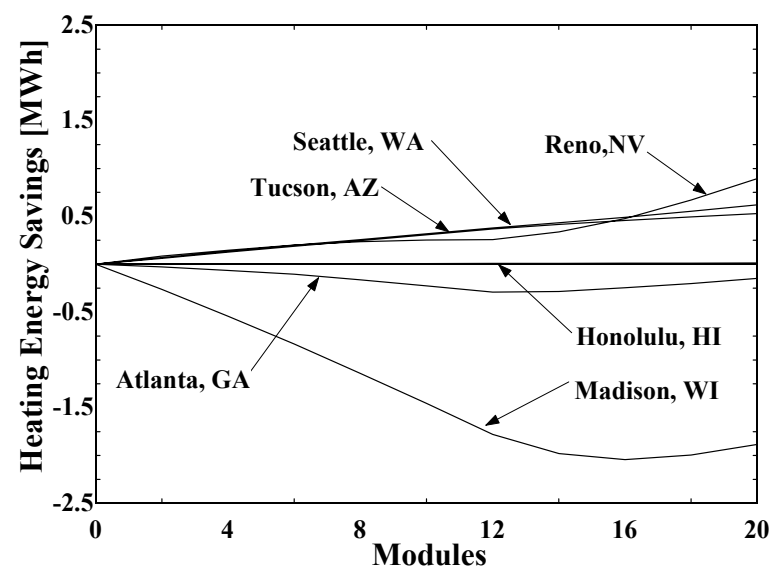

Figure 5: Change in heating load, $85 \mathrm{~lm} / \mathrm{W}$ lighting

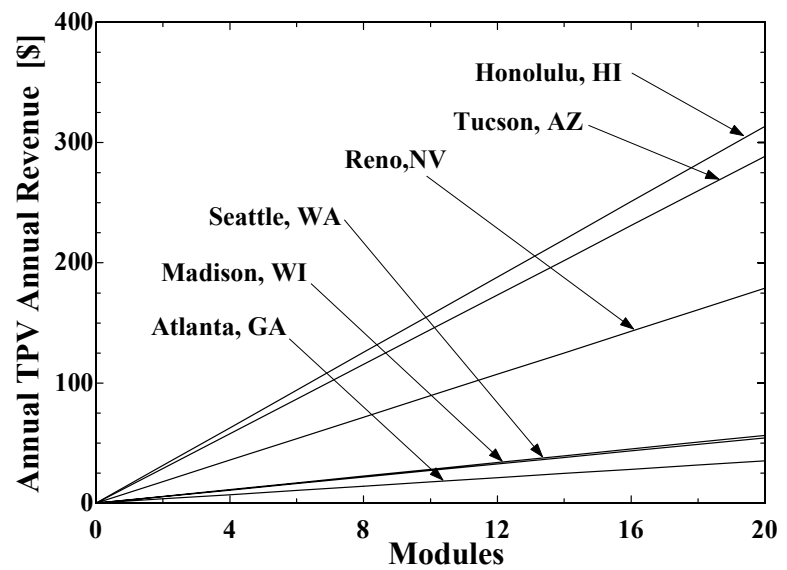

Figure 6: Annual TPV revenue

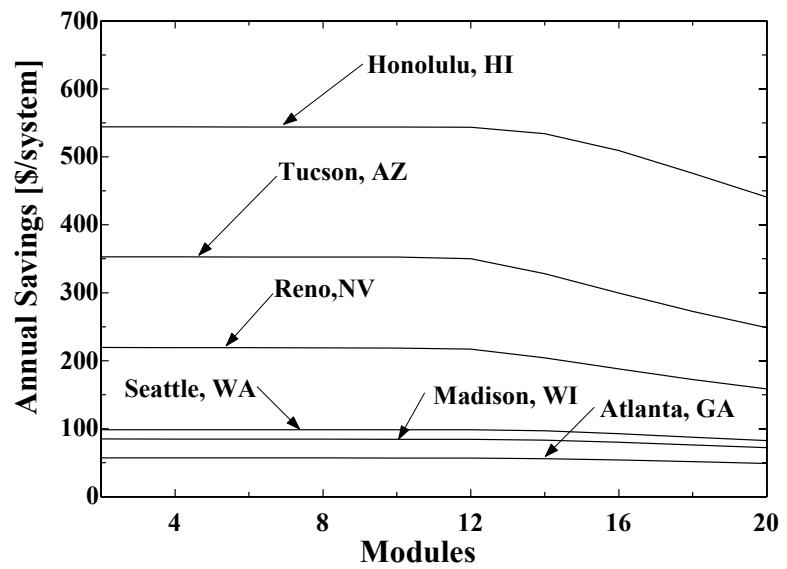

Figure 7: Annual savings, $85 \mathrm{~lm} / \mathrm{W}$ lighting, perfect controls 
APPENDIX B

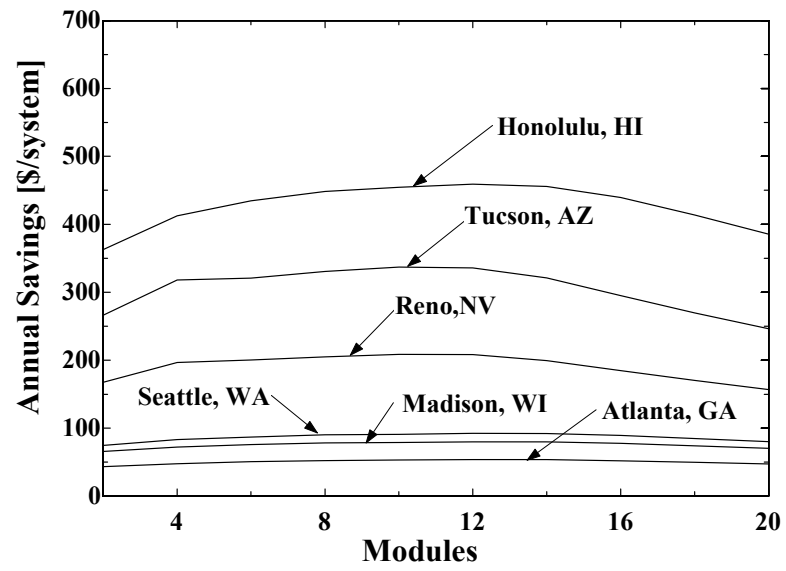

Figure 8: Annual savings $85 \mathrm{~lm} / \mathrm{W}$ dimmable bulbs and ballasts, four stage controls

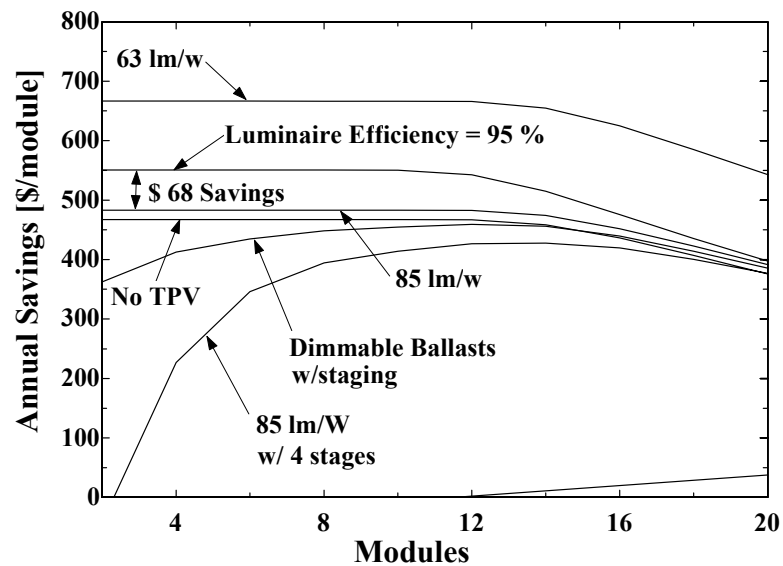

Figure 9: Annual savings, Honolulu, HI 
Table 1: Annual Lighting Load with a Hybrid Lighting System, Tucson, AZ, USA

\begin{tabular}{|c|c|c|c|c|}
\hline & $\begin{array}{c}\text { Number of } \\
\text { Modules }\end{array}$ & \multicolumn{3}{|c|}{ Lighting Load [MWh] } \\
\hline $\begin{array}{c}\text { Auxiliary } \\
\text { Lighting Efficacy } \\
{[\text { lm/W] }}\end{array}$ & & $\mathbf{8 5}$ & $\mathbf{6 3}$ & $\mathbf{8 5}$ \\
\hline Controls & & ideal & ideal & 'real' \\
\hline & 0 & 48.3 & 65.2 & 48.3 \\
& 2 & 42.2 & 57.0 & 43.6 \\
& 4 & 36.1 & 48.7 & 37.2 \\
& 6 & 30.0 & 40.5 & 31.5 \\
& 8 & 23.9 & 32.3 & 25.4 \\
& 10 & 17.9 & 24.1 & 19.1 \\
& 12 & 12.1 & 16.3 & 13.4 \\
& 14 & 8.6 & 11.7 & 9.4 \\
& 16 & 6.8 & 9.1 & 7.3 \\
& 18 & 5.5 & 7.5 & 6.0 \\
& 20 & 4.7 & 6.3 & 5.0 \\
\hline
\end{tabular}

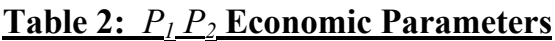

\begin{tabular}{|c|c|c|c|}
\hline Economic Parameters & \multicolumn{3}{|c|}{ Values } \\
\hline Years of Analysis $(n)$ & 10 & 20 & 30 \\
\hline Discount Rate (dis) & $6 \%$ & $6 \%$ & $6 \%$ \\
\hline Fuel Inflation Rate $\left(i n f_{f}\right)$ & $2 \%$ & $2 \%$ & $2 \%$ \\
\hline General Inflation Rate (inf) & $3 \%$ & $3 \%$ & $3 \%$ \\
\hline Initial Down Payment (Down) & $20 \%$ & $20 \%$ & $20 \%$ \\
\hline Mortgage Rate $(m)$ & $6 \%$ & $6 \%$ & $6 \%$ \\
\hline Years of Loan $\left(Y_{L}\right)$ & 10 & 20 & 30 \\
\hline Years of Depreciation $\left(Y_{D}\right)$ & 10 & 20 & 30 \\
\hline Incoming Producing $(C=1)$, or Non-Income Producing $(C=0)$ & 1 & 1 & 1 \\
\hline Income Tax Rate $(t$ bar $)$ & $40 \%$ & $40 \%$ & $40 \%$ \\
\hline Ratio of First Year Miscellaneous Costs to Initial Cost $\left(M_{s}\right)$ & $3 \%$ & $3 \%$ & $3 \%$ \\
\hline Ratio of Resale Value at the End of the Analysis to Initial Cost $\left(R_{v}\right)$ & 0.3 & 0.3 & 0.3 \\
\hline Ratio of Initial Valuation to Initial Cost ( $\mathrm{Val})$ & 1 & 1 & 1 \\
\hline Property Tax Rate $\left(P R_{t x}\right)$ & $3 \%$ & $3 \%$ & $3 \%$ \\
\hline $\overrightarrow{P_{1} / P_{2}}$ & 6.1 & 7.7 & 8.5 \\
\hline
\end{tabular}


Table 3: Break-Even Capital Cost

\begin{tabular}{|c|c|c|c|c|}
\hline Location & $\begin{array}{c}\text { Annual } \\
\text { Savings } \\
{[\$ / \text { module }}\end{array}$ & $\begin{array}{c}\text { Analysis } \\
\text { Period } \\
\text { [yrs] }\end{array}$ & $\mathbf{P}_{1} / \mathbf{P}_{2}$ & $\begin{array}{c}\text { BECC } \\
{[\$ / \text { module }]}\end{array}$ \\
\hline \multirow{3}{*}{ Honolulu, HI } & \multirow{3}{*}{$\$ 459$} & 10 & 6.1 & $\$ 2,800$ \\
\hline & & 20 & 7.7 & $\$ 3,534$ \\
\hline & & 30 & 8.5 & $\$ 3,902$ \\
\hline \multirow{3}{*}{ Tucson, AZ } & \multirow{3}{*}{$\$ 336$} & 10 & $\overline{6.1}$ & $\$ 2,050$ \\
\hline & & 20 & 7.7 & $\$ 2,587$ \\
\hline & & 30 & 8.5 & $\$ 2,856$ \\
\hline \multirow{3}{*}{ Reno, NV } & \multirow{3}{*}{$\$ 210$} & 10 & 6.1 & $\$ 1,281$ \\
\hline & & 20 & 7.7 & $\$ 1,617$ \\
\hline & & 30 & 8.5 & $\$ 1,785$ \\
\hline \multirow{3}{*}{ Seatlle, WA } & \multirow{3}{*}{$\$ 93$} & 10 & 6.1 & $\$ 567$ \\
\hline & & 20 & 7.7 & $\$ 716$ \\
\hline & & 30 & 8.5 & $\$ 791$ \\
\hline \multirow{3}{*}{ Madison, WI } & \multirow{3}{*}{$\$ 80$} & 10 & 6.1 & $\$ 488$ \\
\hline & & 20 & 7.7 & $\$ 616$ \\
\hline & & 30 & 8.5 & $\$ 680$ \\
\hline \multirow{3}{*}{ Atlanta, GA } & \multirow{3}{*}{$\$ 53$} & 10 & 6.1 & $\$ 323$ \\
\hline & & 20 & 7.7 & $\$ 408$ \\
\hline & & 30 & 8.5 & $\$ 451$ \\
\hline
\end{tabular}


Table 4: Break Even Capital Costs, Honolulu, HI

\begin{tabular}{|c|c|c|c|c|}
\hline $\begin{array}{c}\text { Simulation } \\
\text { Type }\end{array}$ & $\begin{array}{c}\text { Annual } \\
\text { Savings } \\
{[\$ / \text { module }]}\end{array}$ & $\begin{array}{c}\text { Analysis } \\
\text { Period } \\
\text { [yrs] }\end{array}$ & $\mathbf{P}_{1} / \mathbf{P}_{2}$ & $\begin{array}{c}\text { BECC } \\
{[\$ / \text { module }]}\end{array}$ \\
\hline \multirow{3}{*}{$\begin{array}{c}\text { Low Efficacy } \\
\text { Lighting } \\
(63 \mathrm{~lm} / \mathrm{W})\end{array}$} & \multirow{3}{*}{$\$ 667$} & 10 & 6.1 & $\$ 4,069$ \\
\hline & & 20 & 7.7 & $\$ 5,136$ \\
\hline & & 30 & 8.5 & $\$ 5,670$ \\
\hline \multirow{3}{*}{$\begin{array}{c}95 \% \\
\text { Luminaire } \\
\text { Efficiency }\end{array}$} & \multirow{3}{*}{$\$ 551$} & 10 & 6.1 & $\$ 3,361$ \\
\hline & & 20 & 7.7 & $\$ 4,243$ \\
\hline & & 30 & 8.5 & $\$ 4,684$ \\
\hline \multirow{3}{*}{$\begin{array}{c}85 \mathrm{~lm} / \mathrm{W} \\
\text { fluorescents, } \\
\text { ideal controls }\end{array}$} & \multirow{3}{*}{$\$ 483$} & 10 & 6.1 & $\$ 2,946$ \\
\hline & & 20 & 7.7 & $\$ 3,719$ \\
\hline & & 30 & 8.5 & $\$ 4,106$ \\
\hline \multirow{3}{*}{$\begin{array}{c}85 \mathrm{~lm} / \mathrm{W} \\
\text { fluorescents, } \\
\text { ideal controls, } \\
\text { no } \mathrm{TPV}\end{array}$} & \multirow{3}{*}{$\$ 466$} & 10 & 6.1 & $\$ 2,843$ \\
\hline & & 20 & 7.7 & $\$ 3,588$ \\
\hline & & 30 & 8.5 & $\$ 3,961$ \\
\hline \multirow{3}{*}{$\begin{array}{c}85 \mathrm{~lm} / \mathrm{W} \\
\operatorname{dimmable} \\
\text { fluorescents, } 4 \\
\text { stage controls }\end{array}$} & \multirow{3}{*}{$\$ 459$} & 10 & 6.1 & $\$ 2,800$ \\
\hline & & 20 & 7.7 & $\$ 3,534$ \\
\hline & & 30 & 8.5 & $\$ 3,902$ \\
\hline \multirow{3}{*}{$\begin{array}{c}85 \mathrm{~lm} / \mathrm{W} \\
\text { fluorescents, } 4 \\
\text { stage controls }\end{array}$} & \multirow{3}{*}{$\$ 428$} & $\overline{10}$ & 6.1 & $\$ 2,611$ \\
\hline & & 20 & 7.7 & $\$ 3,296$ \\
\hline & & 30 & 8.5 & $\$ 3,638$ \\
\hline
\end{tabular}




\title{
NON-IMAGING DEVICES FOR UNIFORM IRRADIANCE ON PLANAR SURFACES FOR PARABOLIC CONCENTRATORS
}

\author{
Dan Dye \\ Byard Wood \\ Mechanical Engineering Department \\ University of Nevada, Reno \\ Reno, NV 89557 \\ dye@unr.edu \\ bdwood@unr.edu
}

\begin{abstract}
The effects that primary parabolic solar concentrator geometry have on secondary non-imaging optics are investigated. In general, the focal length-to-diameter ratio affects the required length of the non-imaging tube as well as the angles of incidence of the impinging rays. The reflective losses at the system's target plane, be it a photovoltaic array, thermal device, or daylight collection device, are a function of the angle of incidence and therefore are related to the focal length-to-diameter ratio of the primary mirror. Analysis is performed via raytracing software to compare refractive and reflective non-imaging devices. It is shown that reflective non-imaging devices can be one-third to one-tenth the length of a refractive device for the same primary dish geometry and have the same transmission efficiency, at the cost of higher incidence angles on the target plane.
\end{abstract}

\section{INTRODUCTION}

A non-imaging (NI) device with a square or rectangular cross-section, used as the secondary optics with a primary parabolic concentrator, can provide near-uniform irradiance on a planar target, such as an array of photovoltaic (PV) cells $[1,2]$. Without the non-imaging device, the concentrated irradiance at the focal plane of a parabolic collector, Fresnel lens, or other solar concentrator is too non-uniform for the efficient operation of a photovoltaic array. Both total internal reflecting (TIR) tubes, such as a solid block of fused silica, and hollow internal reflecting (HIR) tubes, which are hollow tubes with reflective inner walls, have been considered in this investigation. Hollow tubes with internal reflecting surfaces have reflection losses as the rays propagate down the tube, but there is no entrance loss if the tube cross-sectional area is larger than the focal point diameter of the concentrator. TIR tubes have less reflection losses inside the tube, but there are reflection losses at the entrance aperture that depend on the incident angle of the irradiance. When designing a NI device for a PV array, it is then necessary to investigate the transmission losses of the TIR and HIR tubes to decide which is best for the given collector geometry.

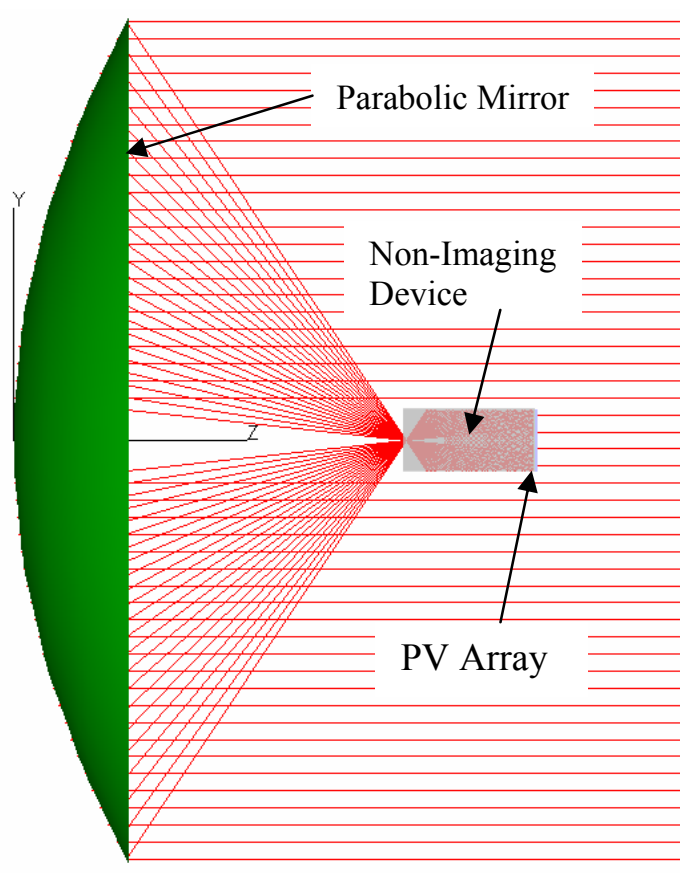

Fig. 1: Solar Concentrating System Used in Analysis Work is underway to develop a full-spectrum solar energy system that produces both solar daylighting and electric power generation [3]. This paper is part of a project to develop a NI device for this full-spectrum solar energy system. The NI device will be responsible for transmitting the infrared portion of the solar spectrum to a GaSb thermophotovoltaic array. This study was performed to see how different primary concentrators would affect the design of the NI tube. 


\section{APPENDIX C}

In this paper, the chosen collector is a one-meter diameter parabolic mirror, shown in Fig. 1, with a concentration ratio of approximately 300 . The focal length-to-diameter (f/D) ratio is the key geometrical relationship of the parabola, and the focal lengths in this analysis ranged from $0.3 \mathrm{~m}$ to $1.1 \mathrm{~m}$, which gives f/D ratios of 0.3 to 1.1 .

\section{ANALYSIS}

\subsection{Computer Modeling}

The raytrace analysis was performed with TracePro v. 3.0, a visual, opto-mechanical 3D analysis program. The solid model of the system was built within TracePro as shown in Fig. 1. The spectral properties of the surfaces were defined, a light source was configured, and the incident irradiance on the cells of the target PV array was analyzed. The target PV array was placed near the focal point in the NI tube, and then moved down the NI tube incrementally until the flux approached a minimum variation. Batches of these files were set up and a Scheme macro was written that ran TracePro through all of the files and saved the results in text files for post-processing.

The number of rays traced from the source was based on the minimum number of rays that produced a reasonably

uniform source flux. Tracing too many rays from the source causes excessive run times with TracePro and was therefore avoided. A parabolic mirror and NI tube system was placed in front of a random distribution ray source and the number of rays traced was increased until the flux variation across the array surface was minimized for a specified length of NI tube. This was also compared to simply putting the array of cells directly in front of the flux source. Up to 45 million rays per-square-meter were traced in the configuration of the source, as illustrated in Fig. 2. It was determined that about 10-15 million rays per square meter was sufficient and a good trade-off between accuracy and required computation time. For the results presented here, approximately 12.5 million rays per-square-meter were traced. For both the TIR and HIR systems, each configuration took approximately 5-6 hours to compute on $1.4 \mathrm{GHz}^{+}$computers with $512 \mathrm{MB}$ RAM.

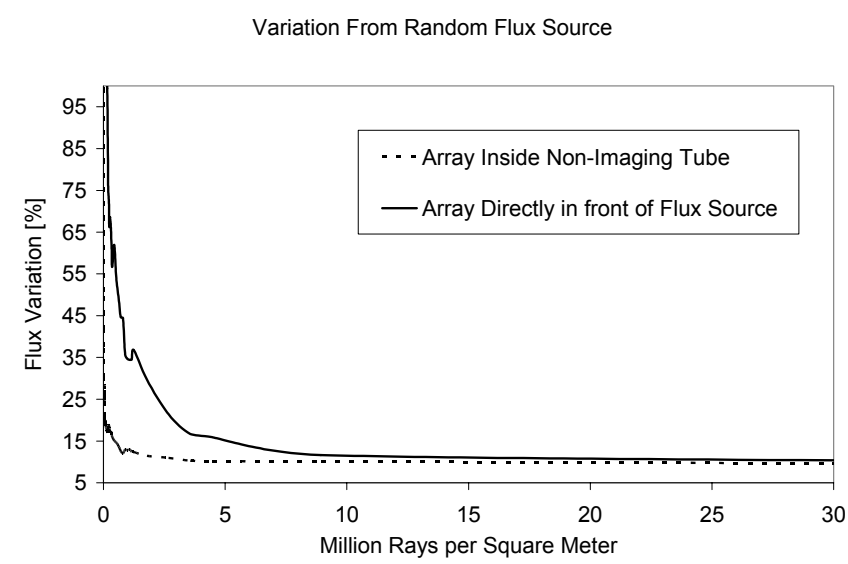

Fig. 2: Flux Variation vs. Ray Flux from Source

\section{$\underline{2.2 \text { Total Internal Reflecting Tube }}$}

In the raytrace analysis of the TIR systems, a solid block of silica was used as the NI tube. The near infrared spectrum of Air Mass 1.5, from $0.7<\lambda<1.8 \mu \mathrm{m}$, was used as the irradiance source, which gives approximately $395 \mathrm{~W} / \mathrm{m}^{2}$ irradiance. This spectrum was chosen because the GaSb thermophotovoltaic array to be used in the full-spectrum solar energy system is responsive to this spectrum [4]. TracePro computes the spectrally dependent index of refraction of the silica which has an average for this spectrum of 1.448 .

\subsection{Hollow Internal Reflecting Tube}

In the raytrace analysis of the HIR tubes, an average surface reflectivity of $97 \%$ was assumed for the NI tube. Due to the lack of known spectral dependence of the reflectivity, it was only necessary to trace a single wavelength, so the TracePro default value of $\lambda=0.5461 \mu \mathrm{m}$ was used. A total of 12.5 million rays per square meter were traced from the source for each iteration, with a source flux of $1 \mathrm{~W} /$ ray. The total flux from the source was then normalized to $395 \mathrm{~W} / \mathrm{m}^{2}$ available in the infrared spectrum so that the transmission efficiencies of the two systems could be compared.

\subsection{Equations of a Parabola}

The equation relating the height y of the parabola, based on the distance $\mathrm{r}$ from the central axis is

$$
y(r)=\frac{r^{2}}{4 f}
$$

where $f$ is the focal point length of the mirror. The slope of the parabola at a point $r$ is given by

$$
\text { slope }=\frac{r}{2 f}
$$




\section{APPENDIX C}

and the angle of the slope $\alpha$ is given in Eq. 3.

$$
\alpha=a \tan \left(\frac{r}{2 f}\right)
$$

The angle $\beta$ of an incident ray on the target plane at the focal point, as measured from the downward-axis, is twice the slope angle. This is shown in Eq. 4.

$\beta=2\left(a \tan \left(\frac{r}{2 f}\right)\right)=2 \alpha$

When a light source larger than the diameter of the mirror is directed normal to the axis, so that all of the reflected rays are concentrated at the focal point, the average incident angle at the focal point is given by Eq. 5, where $\mathrm{R}$ is the outer radius of the mirror.

$$
\bar{\beta}=\frac{\int_{0}^{R} 4 \cdot a \tan \left(\frac{r}{2 \cdot f}\right) \cdot \pi \cdot r \cdot d r}{\pi \cdot R^{2}}
$$

These equations work for systems where the target plane area is much smaller than the collector area, so there is not much shading of the primary mirror. A graph showing how the average incident angle decreases with increasing $f / D$ ratio is shown in Fig. 3.

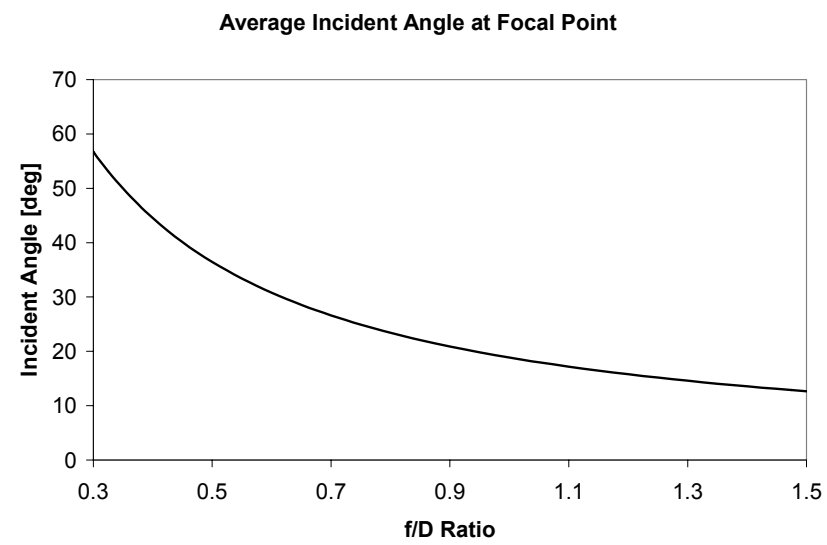

Fig. 3: Average Focal Point Incident Angle vs. f/D Ratio for Parabolic Mirrors

For $\mathrm{f} / \mathrm{D}$ ratios under approximately 0.3 , the average incident angles on the target plane are rather large. This could necessitate the use of anti-reflective coatings on the silica tube entrance and/or on the target surface in order to reduce the reflective losses. Short f/D ratios are desirable for more compact systems, but reflection losses limit how short the system can be made.

An advantage to the TIR system over the HIR system is that upon entering the tube, the rays will straighten and therefore strike the target plane at a more normal angle, thus reducing reflection losses. From Snell's law we can calculate the incident angle on the target plane, $\alpha$, of a ray that has entered the solid silica tube. Modifying Eq. 5 for refraction gives the average incident angle, $\beta$ ', after the rays have entered the silica tube. Fig. 4 shows a comparison of the average incident angle at the exit aperture versus $\mathrm{f} / \mathrm{D}$ ratio of a HIR tube and a TIR tube.

$$
\beta^{\prime}=\frac{\int_{0}^{R} a \sin \left(\frac{n_{\text {air }}}{n_{\text {silica }}} \cdot \sin \left(2 \cdot a \tan \left(\frac{r}{2 \cdot f}\right)\right)\right) \cdot 2 \cdot \pi \cdot r \cdot d r}{\pi \cdot R^{2}}
$$

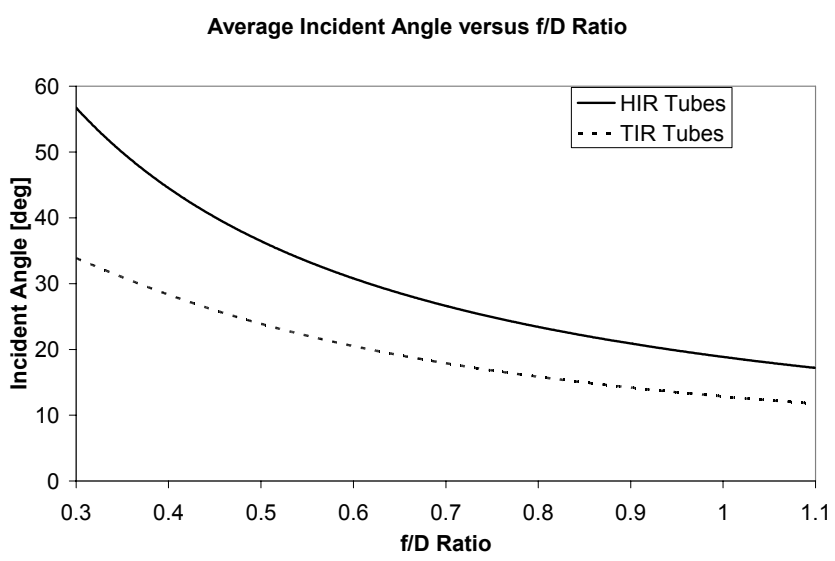

Fig. 4: Average incident angle for HIR and TIR tubes at the exit aperture.

At the focal point of a system with $\mathrm{f} / \mathrm{D}=0.3$, the average incident angle, given by Eq. 5, is approximately 57 degrees from the normal. After the rays have entered the silica refractive tube, the average incident angle on a plane inside the tube is reduced to 34 degrees.

\section{RESULTS}

The raytrace results comparing the five different $\mathrm{f} / \mathrm{D}$ ratios investigated are shown in Figs. 5 and 6. In the first series of graphs, Fig. 5, the minimum cell flux versus NI tube lengthto-width ratio is shown. The minimum flux increases as the symmetry of the incoming rays is broken up, which happens with more reflections off the walls. As expected, the minimum flux on a cell in the HIR tube increases more rapidly than in the TIR tube. This is due to the fact that the rays straighten out in the TIR tube and act as though the primary mirror had a longer $\mathrm{f} / \mathrm{D}$ ratio. For the shortest system analyzed, $\mathrm{f} / \mathrm{D}=0.3$, there was a substantial difference between the transmission efficiencies of the HIR and TIR systems. The TIR system only had an efficiency of $86.6 \%$, while the HIR system had an efficiency of $95.1 \%$. This is obviously due to reflection losses at the entrance aperture of the silica tube. For the rest of the systems, the transmission efficiencies were all in the range of $95-97 \%$. 


\section{APPENDIX C}

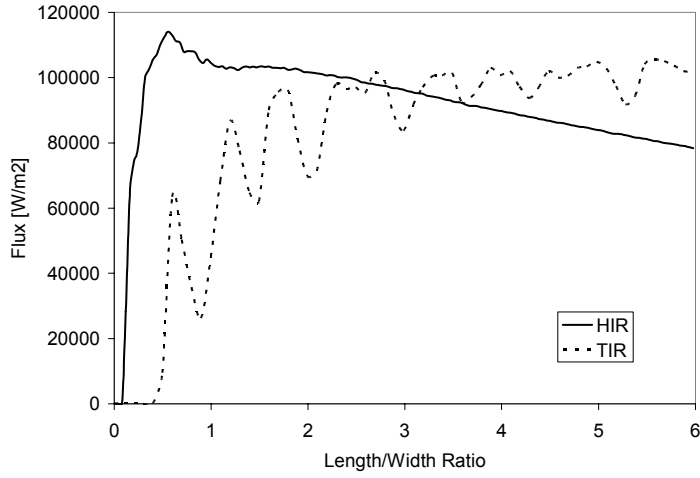

Fig. 5a: $f / D=0.3$

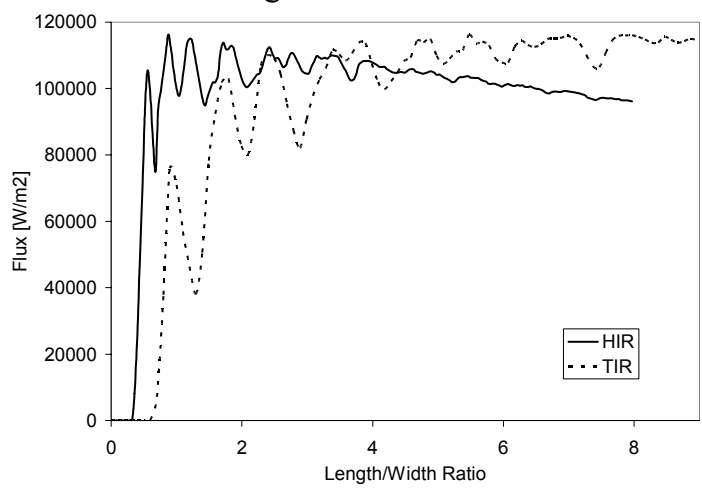

Fig. $5 b: \mathrm{f} / \mathrm{D}=0.5$

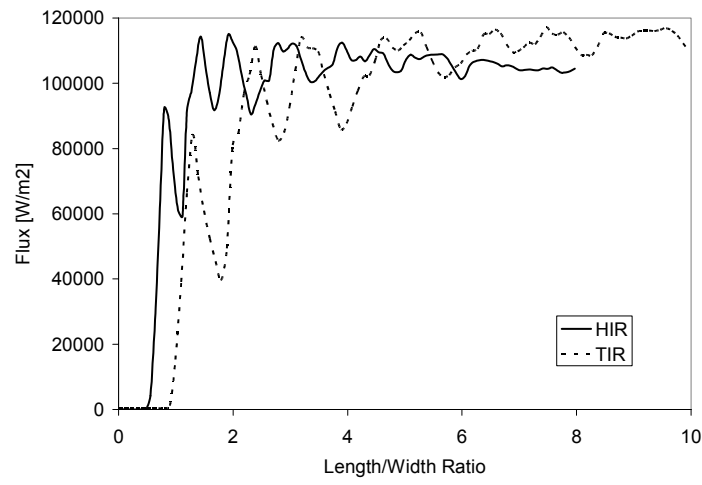

Fig. $5 \mathrm{c}: \mathrm{f} / \mathrm{D}=0.7$

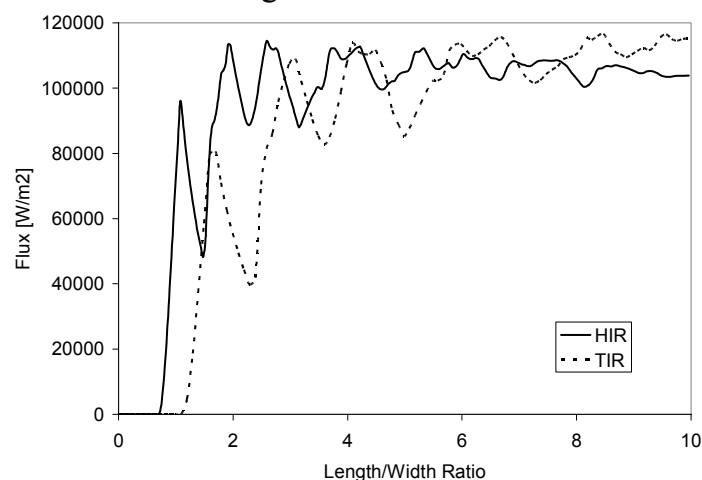

Fig. $5 d$ : $f / D=0.9$

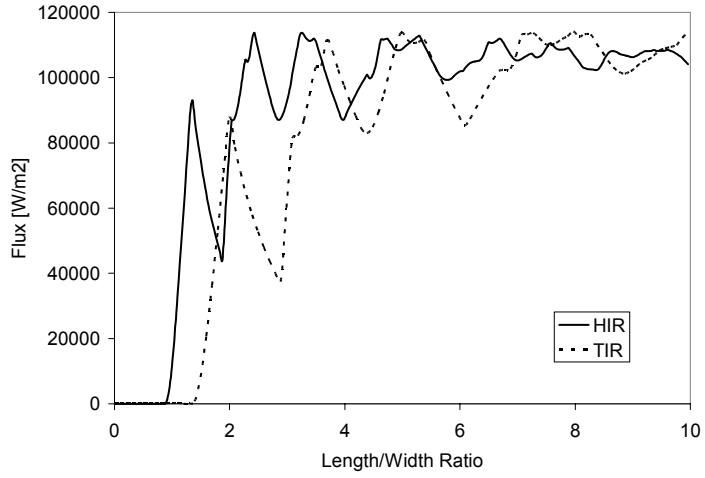

Fig 5e: $\mathrm{f} / \mathrm{D}=1.1$

Fig. 5: Minimum Cell Flux on the Target PV Array vs. NI Tube Length/Width Ratio

In the next series of graphs, Fig. 6, the ratio of minimum flux to average flux versus the tube length-to-width ratio is shown. This ratio shows how well the system homogenizes the flux on the target plane. For the HIR system with the reflective inner walls, the average cell flux decreases linearly with tube length after the first reflection off of the wall, as shown in Fig. 7, but for the TIR system the average flux is essentially constant along the length of the tube after the reflection losses at the entrance. Due to this fact, the location of the highest minimum cell flux in the HIR tube does not coincide with the highest ratio of min/avg flux; the peak min/avg ratio actually occurs further down the tube. In the TIR system, the highest minimum cell flux and peak min/avg flux ratio do coincide, due to the fact that the average remains constant in the TIR tube. When dealing with a reflectorized hollow tube, it would be a mistake to design only for the highest min/avg flux ratio, but designing for this in a TIR system would be acceptable.

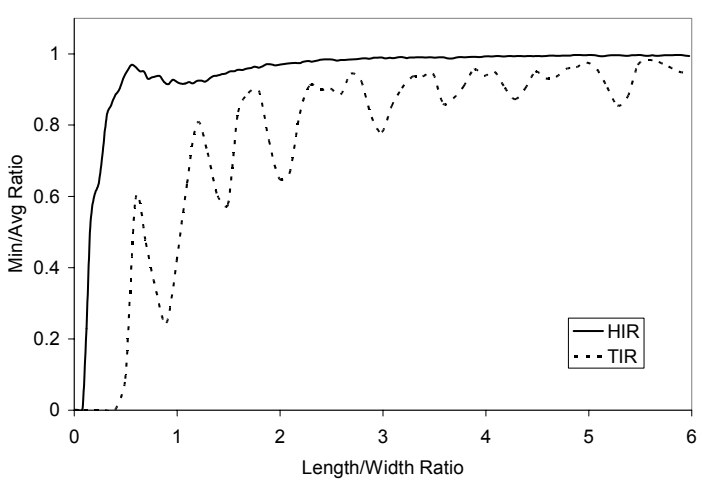

Fig. $6 \mathrm{a}: \mathrm{f} / \mathrm{D}=0.3$ 


\section{APPENDIX C}

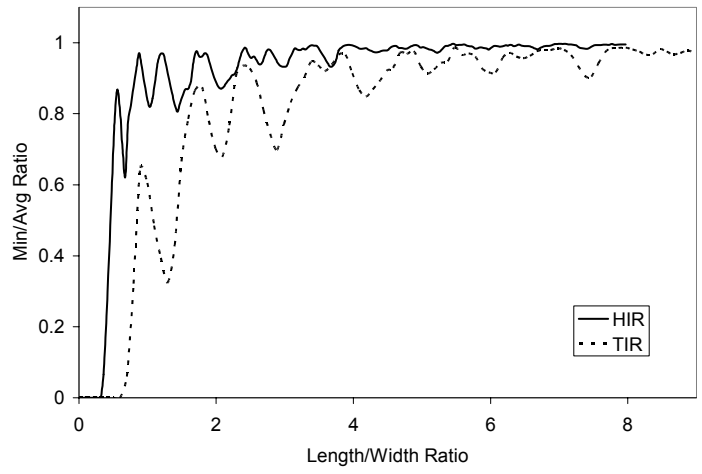

Fig. $6 \mathrm{~b}: \mathrm{f} / \mathrm{D}=0.5$

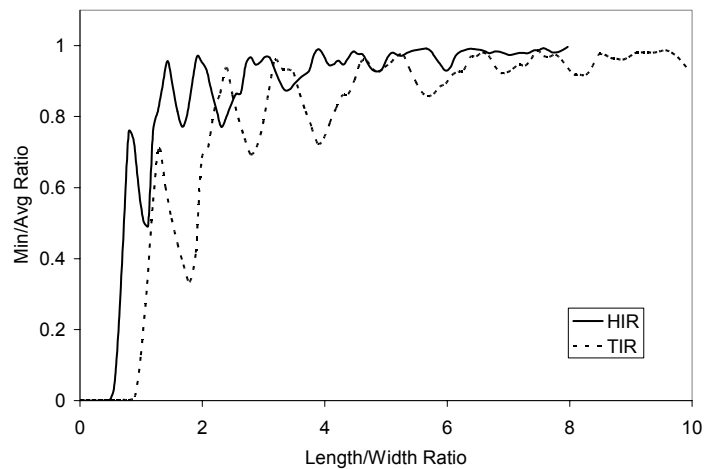

Fig. $6 c: f / D=0.7$

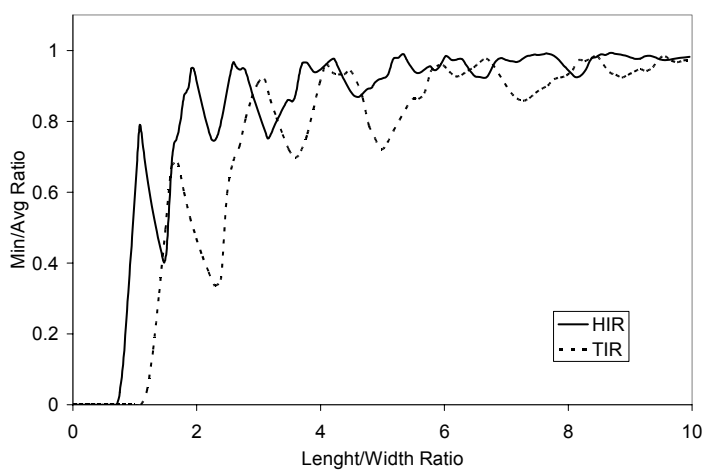

Fig. $6 \mathrm{~d}$ : $\mathrm{f} / \mathrm{D}=0.9$

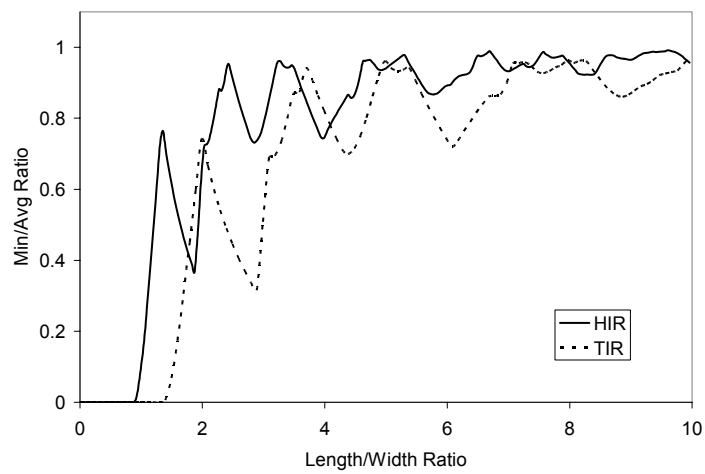

Fig. $6 \mathrm{e}: \mathrm{f} / \mathrm{D}=1.1$

Fig. 6: Minimum/Average Flux Ratio vs. NI Tube Length/Width Ratio

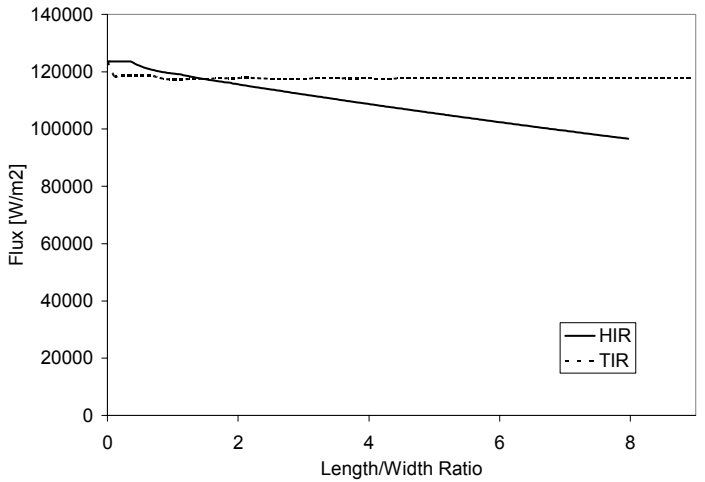

Fig. 7: Average Flux vs. NI Tube L/W Ratio for $\mathrm{f} / \mathrm{D}=0.5$

\section{CONCLUSIONS}

The results for the HIR and TIR systems are presented in Tables 1 and 2, respectively. In these tables, the peak minimum flux is given for each $\mathrm{f} / \mathrm{D}$ ratio and the corresponding non-imaging tube length to width $(\mathrm{L} / \mathrm{W})$ ratio, minimum-to-average flux ratio, and transmission efficiency. The main difference between the two systems is the required length-to-width ratio of the non-imaging tube. The TIR tube requires approximately three to ten times the length as the HIR tube, depending on the f/D ratio of the primary mirror. The fact that with short $\mathrm{f} / \mathrm{D}$ ratios there will be high reflection losses at the entrance aperture of the silica tube requires some attention. Steep entrance angles would not be desirable for most receivers, such as an array of PV cells, but dishes with short f/D ratios are desirable in some aspects.

TABLE 1: HIR RESULTS

\begin{tabular}{|c|c|c|c|c|c|}
\hline f/D Ratio & $\mathbf{0 . 3}$ & $\mathbf{0 . 5}$ & $\mathbf{0 . 7}$ & $\mathbf{0 . 9}$ & $\mathbf{1 . 1}$ \\
\hline $\begin{array}{c}\text { Peak Minimum } \\
\left.\text { Flux [W/m } \mathbf{W}^{2}\right]\end{array}$ & 114028 & 116255 & 114790 & 114481 & 113775 \\
\hline $\begin{array}{c}\text { Corresponding } \\
\text { NI L/W Ratio }\end{array}$ & 0.558 & 0.876 & 1.912 & 2.590 & 2.430 \\
\hline Min/Avg Ratio & 0.969 & 0.971 & 0.969 & 0.967 & 0.954 \\
\hline $\begin{array}{c}\text { Transmission } \\
\text { Efficiency }\end{array}$ & 95.12 & 96.86 & 95.79 & 95.72 & 96.49 \\
\hline
\end{tabular}

TABLE 2: TIR RESULTS

\begin{tabular}{|c|c|c|c|c|c|}
\hline f/D Ratio & $\mathbf{0 . 3}$ & $\mathbf{0 . 5}$ & $\mathbf{0 . 7}$ & $\mathbf{0 . 9}$ & $\mathbf{1 . 1}$ \\
\hline $\begin{array}{c}\text { Peak Minimum } \\
\text { Flux [W/m }{ }^{2} \text { ] }\end{array}$ & 105514 & 116215 & 117175 & 116587 & 114159 \\
\hline $\begin{array}{c}\text { Corresponding } \\
\text { NI L/W Ratio }\end{array}$ & 5.578 & 5.478 & 7.470 & 8.466 & 7.968 \\
\hline Min/Avg Ratio & 0.983 & 0.988 & 0.987 & 0.984 & 0.963 \\
\hline $\begin{array}{c}\text { Transmission } \\
\text { Efficiency }\end{array}$ & 86.84 & 95.13 & 95.98 & 95.80 & 95.89 \\
\hline
\end{tabular}




\section{APPENDIX C}

The length-to-width ratio vs. f/D ratio is shown in Fig. 8. Both curves follow roughly the same shape, except in the short $\mathrm{f} / \mathrm{D}$ region of the TIR tube where reflection losses at the entrance change the angular distribution of the incoming rays, i.e. rays with larger incident angles at the entrance aperture are lost and therefore the rays that do enter the tube have an angular distribution closer to that of a system with a longer f/D ratio.

Length to Width Ratio vs. f/D Ratio

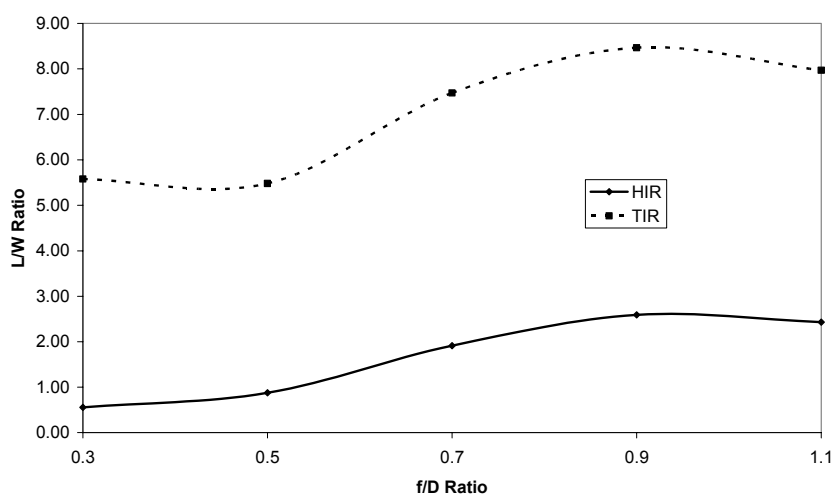

Fig. 8: Length to Width Ratio vs. f/D Ratio at the Peak Minimum Flux Point

Preliminary tests show that the NI tube length-to-width ratio holds for TIR tubes with varying widths, but not for HIR tubes. This could be due to the fact that the flux is more homogenized in the TIR tube and therefore it is a more robust or stable system. At the very least the length to width ratio given in Fig. 8 or Tables 1 and 2 for TIR tubes can provide an estimate of the required tube length based on a certain $f / D$ ratio and target plane width. One thing to note is that the lengths used here are from the focal point to the array plane. A shorter length can be used if the focal point is placed at a distance in front of the tube instead of directly at the entrance aperture. For a silica TIR tube, this would reduce the high concentration of energy at the entrance aperture and thus reduce the heat flux if it is a problem. However, having the focal point be at the entrance aperture of the NI tube relaxes the tracking accuracy. Depending on the concentration ratio, the tracking accuracy can be reduced substantially which would lead to a more robust system.

For the full-spectrum collector/receiver, which has an f/D ratio of approximately 0.35 , a hollow NI tube will probably be utilized, but more investigation will be performed on this exact system since the thermophotovoltaic array to be used is not square. The GaSb PV cells with an anti-reflection coating can accept incident angles up to 60 degrees, so the incident angles at the exit aperture of the HIR system would be acceptable. The HIR system would also have the added benefit of keeping the entire collector more compact, as well as less expensive. The required length of a solid TIR nonimaging device would increase the weight at the antenna of the system and increase the torque on the structure and tracking mechanism.

\section{ACKNOWLEDGEMENTS}

This project was funded in part by:

Cooperative Agreement DE-FC26-01NT41164

Thanks also go to Oak Ridge National Laboratory, J.X. Crystals, the Energy Systems Laboratory at the University of Nevada, Reno, and all team members involved in the Full-Spectrum Solar Energy Systems and Hybrid Lighting Project.

\section{REFERENCES}

(1) D. Dye, B.D. Wood, L. Fraas, and J. Muhs, “Optical Design of an Infrared Non-Imaging Device for a FullSpectrum Solar Energy System," Proceedings of the International Solar Energy Society Conference, 2003. (2) J.J. O'Gallagher, R. Winston, and R. Gee, "NonImaging Solar Concentrator with Near Uniform Irradiance for Photovoltaic Arrays," Nonimaging Optics: Maximum Efficiency Light Transfer VI, Proceedings of SPIE Vol. 4446, 2001

(3) J. Muhs, "Design and Analysis of Hybrid Solar Lighting and Full-Spectrum Solar Energy Systems," Proceedings of the American Solar Energy Society's SOLAR 2000 Conference

(4) L. Fraas, W.E. Daniels, and J. Muhs, "Infrared Photovoltaics for Combined Solar Lighting and Electricity for Buildings," Proceedings of the $17^{\text {th }}$ European Photovoltaic Solar Energy Conference, 2001 